\title{
LA ACRÓPOLIS DE ATEGUA. NUEVOS DATOS ARQUEOLÓGICOS SOBRE SU ORIGEN Y EVOLUCIÓN HISTÓRICA
}

\section{THE ACROPOLIS OF ATEGUA. NEW ARCHAEOLOGICAL DATA ON ITS ORIGIN AND HISTORICAL EVOLUTION}

\author{
Fuertes Santos, M. C. ${ }^{1}$; Borrego de la Paz, J. D. ${ }^{2}$; Carrasco Gómez, I.3; Jiménez \\ Hernández, A.4; Romero Paredes, C. ${ }^{5}$ \\ Recibido: 07/105/2021 - Aceptado: 17/11/2021 \\ DOI: https://doi.org/10.5944/etfi.14.2021.31756
}

\section{Resumen}

Se exponen en este trabajo los datos arqueológicos obtenidos tras varias obras de consolidación efectuadas sobre las estructuras excavadas durante los años 80 del siglo XX del edificio de la acrópolis. El uso de una metodología arqueológica correcta, utilizada durante el seguimiento del control de las obras, ha permitido acercarnos a la cronología de su construcción y a su evolución histórica.

\begin{abstract}
The archaeological information obtained after several consolidation works carried out on the structures excavated during the 80 's of the $20^{\text {th }}$ century in the acropolis building is exposed in this work. The archaeological methodology applied during the supervisión of these works, has allowed us to get closer to the chronology of its construction and its historical evolution.
\end{abstract}

Palabras clave

Arqueología; edificio protohistórico; Hierro I; ciudad romana; fortaleza tardo-islámica.

Keywords

Archaeology; Protohistoric building; Iron I; Roman city; Late Islamic fortress.

\footnotetext{
1. Consejería de Cultura y Patrimonio Histórico, Junta de Andalucía, camino.fuertes@juntadeandalucia.es

2. Antiguas Ciudades de Andalucía, juandepost@hotmail.com

3. Universidad Pablo de Olavide, icarrasco@upo.es

4. Grupo PAIDI TEP 211 Conservación Preventiva del Patrimonio Construido, ajharqu@yahoo.es

5. Grupo PAIDI Hum 639 Implicaciones tecnológicas en procesos arqueológicos, museológicos y de Gestión Patrimonial, carmen67.romero@gmail.com
} 


\section{INTRODUCCIÓN}

Gracias a su excelente estado de conservación, la acrópolis es el edificio más llamativo del yacimiento de Ategua ${ }^{6}$. Las primeras excavaciones se realizaron en los años 80 del siglo XX y afectaron a una parte importante de su cumbre y de su lado occidental, así como al espacio ocupado por el ángulo noreste de la fortaleza tardo-islámica y por la torre del homenaje de esa fortificación ${ }^{7}$. No se conocen los datos relativos a la excavación de los muros en alzado que actualmente pueden ser observados, si bien su excavador propuso en primera instancia un origen medieval para los mismos (véase nota 7) (figura I).

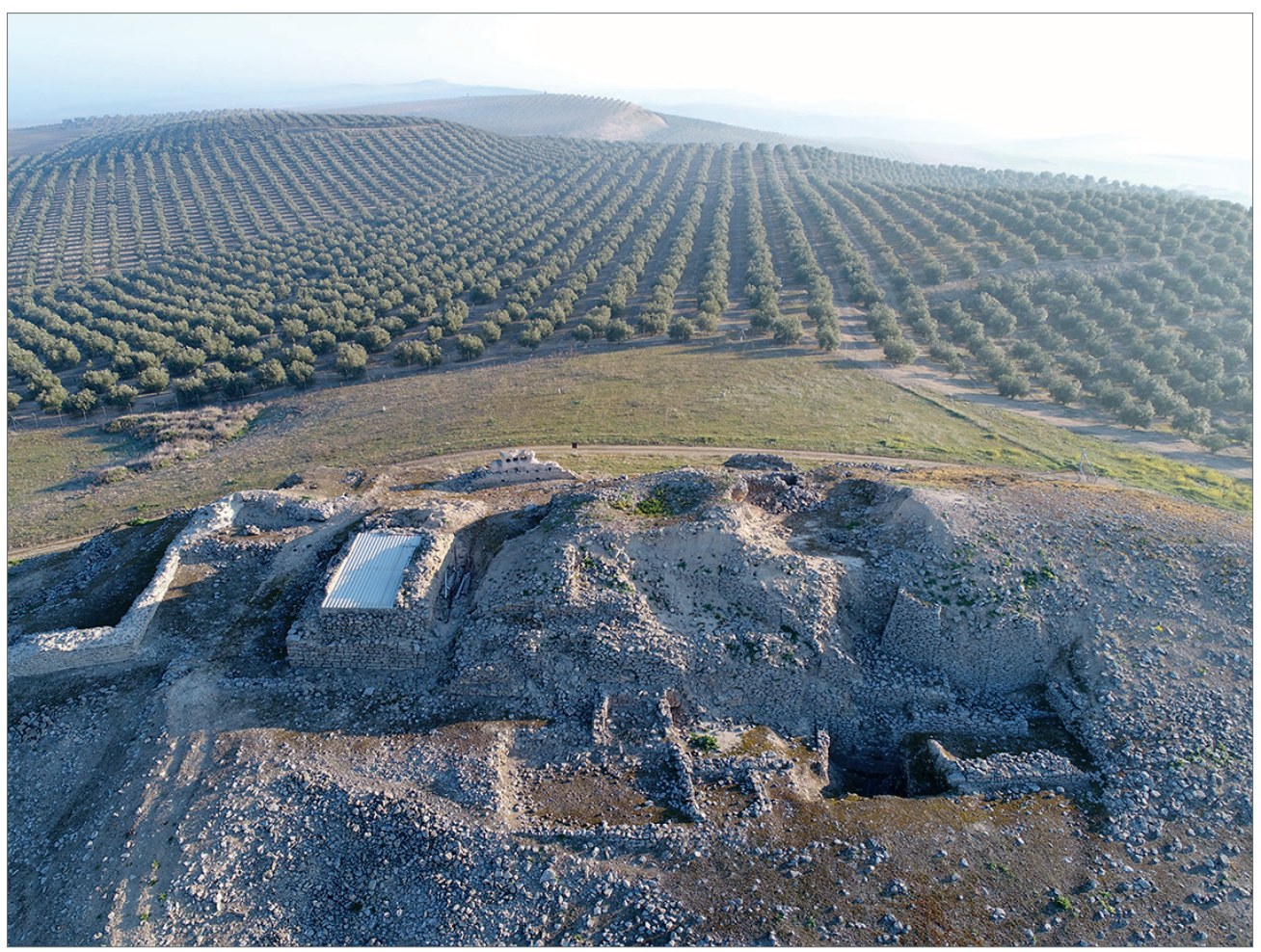

FIGURA 1. VISTA AÉREA DE LA ACRÓPOLIS EN 2017, ANTES DE LOS TRABAJOS DE CONSOLIDACIÓN. DE IZQUIERDA A DERECHA Y DE ARRIBA A ABAJO: ÁNGULO NORESTE DE LA FORTALEZA TARDO ISLÁMICA; CIMENTACIONES DE LA TORRE DEL HOMENAJE DE ESA FORTALEZA, TRAMO EN TAPIAL DE LA CERCA ORIENTAL DE LA FORTALEZA TARDO-ISLÁMICA, CUMBRE Y FRENTE OCCIDENTAL DEL EDIFICIO; EN LA BASE PARAMENTOS RELACIONADOS CON LA URBANIZACIÓN INTERNA DE LA FORTALEZA TARDO-ISLÁMICA. C A. López

6. Todas las obras realizadas en la acrópolis de Ategua han sido promovidas y financiadas por la Consejería de Cultura y Patrimonio Histórico de la Junta de Andalucía.

7. «Se diferencia claramente la muralla indígeno-romana de la medieval en el tipo de estructura y sobre todo en la diferencia constructiva de ambas, con utilización de bloques mayores y tallados exprofeso en la ciudad antigua y reaprovechados en la medieval islámica. De este momento deben proceder algunos muros en talud y que momentáneamente se encuentran sin identificar correctamente, lo mismo que una torre aislada dentro de un complejo defensivo situado en la zona más alta del yacimiento, con reutilizaciones posteriores abundantes» (sic) (Martín Bueno y Cancela 1983: 1002). 
Se trata de una colina artificial que se levanta en la zona más alta del cerro en el que se emplaza la ciudad amurallada. Su planta aún no ha podido ser definida y en alzado parece la de una pirámide truncada, o la de un trapecio, con la base más ancha que la cumbre que pudo estar amesetada. Su lado oriental funcionaba, además, como muralla indígeno-romana y así, como muralla, siguió funcionando hasta el abandono de la ciudad, hacia el siglo XV (vid. infra). Se ha excavado algo menos de la mitad de su longitud $-35 \mathrm{~m}$ dirección norte-sur- y algo menos del total de su anchura -20 m dirección este-oeste-. En uno de los cortes excavados en los años 8o, el conocido como el CM Gi6 (Fuertes 20I7: 72 y s.), se documentó su cimentación y alzado que, en algunas zonas, supera los $9 \mathrm{~m}$. de altura. Se construyó a base de mampuesto de mediano y pequeño tamaño de piedra local -biocalcarenita- extraída de las canteras que rodean al cerro sobre el que se asienta. La ausencia de mortero entre las piedras nos llevó a pensar que aquéllas se habían dispuesto en seco, si bien el control arqueológico de las obras de consolidación de los paramentos ha permitido demostrar que estuvieron unidas con margas muy plásticas e impermeables. No hemos constatado la presencia de cal (vid. infra) (figura 2).

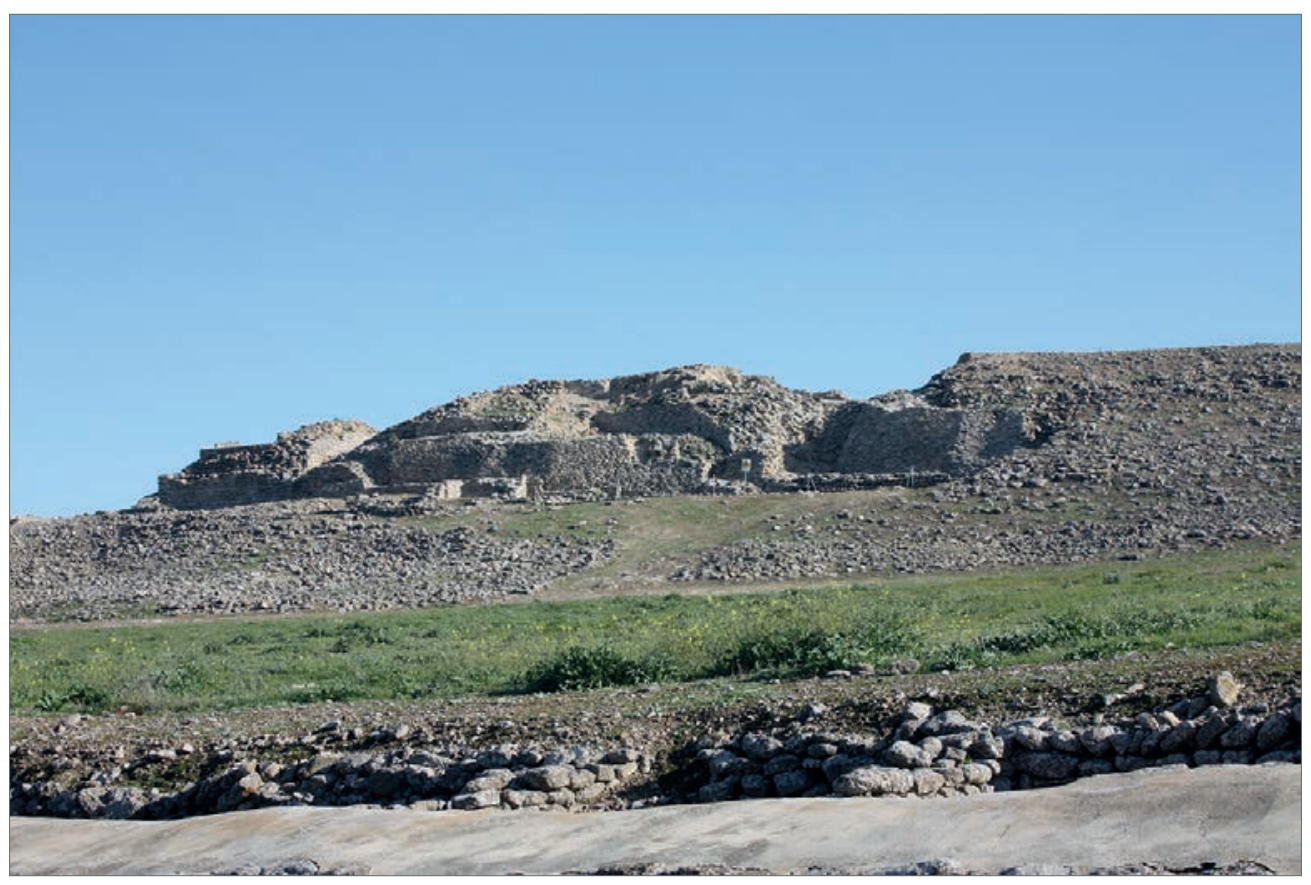

FIGURA 2. VISTA DESDE EL OESTE DEL LADO EXCAVADO DE LA ACRÓPOLIS. A LA IZQUIERDA TORRE DEL HOMENAJE DE LA FORTALEZA TARDO-ISLÁMICA. A SU DERECHA MUROS-CAJONES DEL EDIFICIO PROTOHISTÓRICO. AÑO 2020. (C) M. ${ }^{\mathrm{a}} \mathrm{C}$. Fuertes

El lado occidental de la acrópolis se presenta como una pared vertical de trazado irregular formada por la unión de distintas estructuras a modo de cajones de tres lados, casi siempre ataluzadas, adyacentes unas con otras en diferentes planos arquitectónicos y de forma escalonada. Hasta el momento se han identificado i8 de estos cajones -mejor o peor conservados- alineados en tres líneas yuxtapuestas. La 
más adelantada, de dirección norte-sur, la conforman seis de ellos ${ }^{8}$ que soportan, en el tramo excavado, el empuje de, al menos, otros siete que se disponen en una segunda hilada, cuatro de ellos con la misma orientación que los anteriores ${ }^{9}$ los otros tres construidos con una orientación distinta, noreste-suroeste ${ }^{\text {to. }}$ En una tercera línea son visibles otros tres cajones ${ }^{\mathrm{II}}$ el núcleo de un cuarto cuya pared sustentante ha desaparecido y, tal vez, el denominado i8 en la cumbre (figura 3).

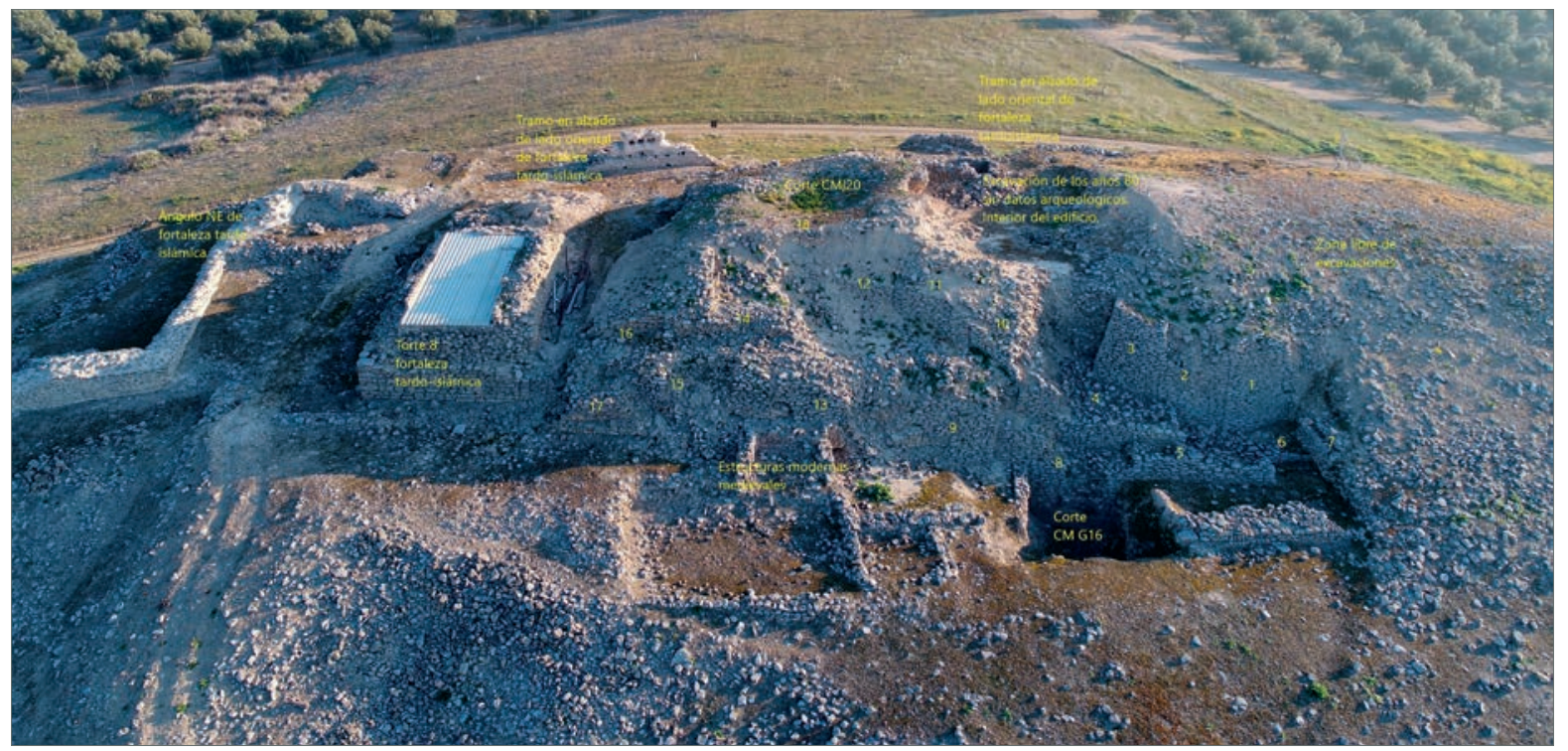

FIGURA 3. SOBRE IMAGEN DE FIGURA 1, IDENTIFICACIÓN DE LOS MURO-CAJÓN DEL FRENTE OCCIDENTAL DE LA ACRÓPOLIS Y DE OTROS ESPACIOS Y ESTRUCTURAS RELACIONADOS CON EL EDIFICIO. C Interpretación M. ${ }^{a}$ C. Fuertes sobre fotografía de A. López

Cada uno de estos cajones de piedra está delimitado por tres paredes levantadas con mampuestos dispuestos en líneas horizontales, que actúan a modo de muros de contención soportando un relleno de piedras colocadas sin orden aparente. Para aumentar su inercia frente a los empujes horizontales, se ataluzaron y se escalonaron según las paredes iban ganando altura. Son perfectamente visibles las líneas de separación de cada uno de estos tramos murarios, lo que confirma que fueron construidos de manera exenta. Las verticales de estas juntas no son coincidentes unas con otras lo que favorece la estabilidad del conjunto. Por el momento, no podemos determinar cómo está planificada la obra, si bien es muy posible que avanzara de este a oeste. El lado oriental funcionaría, además, como línea de muralla. La importancia de esta masa arquitectónica no solo radica en su monumentalidad que es manifiesta, sino en la posible antigüedad de la misma.

El lado oriental de esta colina funcionaría como muralla de la ciudad desde algún momento indeterminado de la protohistoria y fue reutilizado, también,

\footnotetext{
8. Identificados como $5,8,9,13,15$ y 17 .

9. $L o s n^{\circ} 4,6,14,16$ y tal vez el 7 .

10. $\operatorname{Los} n^{\circ} 10,11$ y 12 .

11. $\operatorname{Los}^{\circ} 1,2$ y 3 .
} 
como muralla de la fortaleza tardo-islámica. De este último momento se han documentado dos de sus tramos, uno de los cuales ya fue descrito y dibujado por el arqueólogo Blanco Freijeiro, junto con lo que hoy se conoce como la torre del homenaje de la fortaleza tardo-islámica o torre 8 y que él supuso descubierta durante las excavaciones de los años 30 y que interpretó como un posible castellum aquae. Los vestigios arqueológicos que Blanco visualizó en los años 6o no le permitieron entender ante que se encontraba: el lado oriental de una muralla y una torre tardoislámica construidas sobre los restos de un edificio protohistórico ${ }^{12}$.

Los trabajos realizados por nosotros en la acrópolis de Ategua han tenido como fin principal la consolidación del edificio, cuyo estado de conservación, después de su excavación y su exposición a la intemperie tras más de treinta años, era ruinoso (figura I). Se han llevado a cabo dos campañas sobre la misma, la primera de ellas entre diciembre de 2018 y enero de $2019^{13}$ y la segunda entre diciembre de $2019 \mathrm{y}$ febrero de $202 \mathrm{O}^{\mathrm{I} 4}$. Previamente a estas dos actuaciones, en 20I4, se intervino sobre el lienzo de la muralla tardo-islámica que se levanta sobre el lado oriental del edificio, el estudiado por Blanco (vid. supra) y que, en ese momento, estaba a punto de desplomarse ${ }^{15}$. Con esta primera actuación se pusieron en marcha los trabajos de consolidación de la mayor parte de las estructuras excavadas en los años 8 o del pasado siglo y se arbitró la metodología para poder llevarlos a cabo, cuyo objetivo principal ha sido y sigue siendo, el de conservar el bien con rigurosidad sin poner en riesgo ni su naturaleza arqueológica, ni la estética que le ha otorgado el paso del tiempo.

La información que aquí presentamos se corresponde con los resultados de dos controles de movimientos de tierra. El interés de exponer en este trabajo los resultados de dos actuaciones arqueológicas de apoyo a obras de consolidación, se justifica por la necesidad de dar a conocer el trabajo de interpretación de los restos excavados en los años 80 y, sobre todo, por la vinculación de los mismos a su realidad estratigráfica y, en la medida que ha sido posible, cronológica. Partimos de un conocimiento muy exiguo sobre la acrópolis. Desconocemos su planta

12. (...) «cuesta trabajo creer que el Castillejo tuviese en época musulmana tanta importancia como para hacer unas obras de fortificación de esta magnitud, a menos que se encontrasen hechas en su mayor parte» (Blanco 1983: 14 y s., fig. 3, lám. II.3).

13. Control arqueológico de movimiento de tierras sobre obras de conservación y consolidación urgente de la cara oeste de la acrópolis del yacimiento arqueológico de Ategua, Córdoba. Director del control del movimiento de tierras: D. Juan de Dios Borrego de la Paz. Director de obra: D. Manolo Pedregosa Cruz. Arquitecto Técnico: D. Luis Olmedo Gordillo. Dibujante Arqueológico: D. Diego Gaspar Guardado. Empresa Adjudicataria: Arqueobética S.L. Coordinadora del Enclave Arqueológico y de todos los trabajos: Dña. Camino Fuertes Santos.

14. Control de Movimientos de tierra sobre obras de conservación y consolidación urgente de la acrópolis (caras norte, oeste y este) del yacimiento arqueológico de Ategua, Córdoba. Control de movimientos de tierras sobre las obras de cortafuegos y conservación urgente de las Torres 2 y 3 del recinto ibero-romano de Ategua afectadas por el fuego. Directora del control de movimiento de tierras: Dña. Inmaculada Carrasco Gómez. Técnicos arqueólogos: Dña. Carmen Romero Paredes y D. Alejandro Jiménez Hernández. Director de obra: D. Manolo Pedregosa Cruz. Arquitecto Técnico: D. Luis Olmedo Gordillo. Dibujante Arqueológico: D. Diego Gaspar Guardado. Empresas Adjudicataria: Arqueobética S.L e Hijos de Francisco Campos. Coordinadora del Enclave Arqueológico y de todos los trabajos: Dña. Camino Fuertes Santos.

15. Control Arqueológico de movimiento de tierras, sobre obras de conservación y consolidación en el yacimiento arqueológico de Ategua, Córdoba (ABI/305/2014). Directora del control del movimiento de tierras: Dña. Camino Fuertes Santos. Director de obra: D. Manolo Pedregosa Cruz. Arquitecto Técnico: D. Luis Olmedo Gordillo. Dibujante Arqueológico: D. Diego Gaspar Guardado. Empresas Adjudicataria: Hijos de Francisco Campos. Coordinadora del Enclave Arqueológico y de todos los trabajos: Dña. Camino Fuertes Santos, (Fuertes 2014). 
arquitectónica completa, suponemos - pero no tenemos la certeza absoluta- su relación con la muralla indígena-romana y vamos entendiendo la manera en que se perpetuó su uso hasta el abandono final de la ciudad en época bajo-medieval. Estamos empezando a entrever su cronología si bien las dudas que hoy envuelven al edificio serán mejor resueltas cuando se consigan poner en marcha nuevas excavaciones arqueológicas.

\section{ESTADO DEL CONOCIMIENTO SOBRE ATEGUA PREVIO AL INICIO DE LAS OBRAS EN LA ACRÓPOLIS (figura 4)}

En un estudio de algunos de los materiales cerámicos recuperados en las excavaciones de los años 80 del siglo pasado almacenados en el Museo Arqueológico de Córdoba, se detectó la presencia de varios fragmentos de cerámica campaniforme (Martín de la Cruz et al. 20I7). La ausencia de una estratigrafía plausible para los mismos y la posibilidad de que los materiales fueran seleccionados de sus contextos, impide asegurar con total rotundidad el uso del cerro, como lugar de habitación, durante la etapa calcolítica ${ }^{16}$. Por otra parte, es muy posible que Ategua estuviera ocupada no solo desde el Calcolítico, sino incluso desde momentos más tempranos, como ocurre, y por poner solo un ejemplo, en el cercano yacimiento de Torreparedones ${ }^{17}$. Se dan circunstancias propicias para ello: ocupa una zona alta con una buena visibilidad del territorio circundante; debió estar muy bien provisto de caza y pesca -el cerro está rodeado por dos ríos en sus lados sur y oeste: los actuales Guadajoz y un afluente por la derecha de éste, el Fontalba-; hay presencia de agua potable -un manantial de agua, La Fuente de Teba, brota a los pies del cerro en su lado occidental-; las tierras que lo rodean son extraordinariamente fértiles y se localiza en lo que fue, en su momento, una importante vía de comunicación entre las actuales ciudades de Córdoba y Granada.

El sitio sí está seguro ocupado desde el Bronce Final y así lo certifica la presencia de una necrópolis de incineración y de materiales cerámicos de este momento asociados a contextos de habitación. A partir de este período histórico los hallazgos, dispersos en cuanto a fechas, nos van dejando constancia del uso del espacio desde el siglo $\mathrm{X}$ a.d.e hasta el final de la etapa bajo medieval ${ }^{18}$.

La ciudad histórica adquiere relevancia debido al conflicto bélico que enfrentó a las tropas cesarianas con las pompeyanas a mediados del siglo I a.d.e. y que se saldó con la rendición de la ciudad permitiendo la toma de Córdoba por parte de

16. Sobre la estratigrafía del corte 2 A' abierto en 1980: «5. Paquete de niveles prerromanos conteniendo materiales coloniales (...) junto con cerámicas de tipo indígena pintadas y a torno. En los subniveles inferiores del conjunto materiales que enlazan con el final de la Edad del Bronce. Cerámicas a mano, e incluso un fragmento de campaniforme procedente de estratos más profundos. 6. Nivel que alcanza una potencia extraordinaria (en esta zona $250 \mathrm{~cm}$.) hasta llegar al nivel de la roca. Se suceden materiales fundamentalmente pertenecientes a un nivel de Bronce Incial, Eneolítico, muy potente (...). En este grueso conjunto perteneciente a la Edad del Bronce y en este punto la estratigrafía ha permitido dividir e individualizar más de diez niveles y subniveles (...)». (Martín Bueno 1983: 229 y s.).

17. Al respecto véase Martínez 2014: 19 y ss. y más en profundidad Martínez et al. 2014.

18. La historia de la investigación puede ser consultada en Fuertes et al. 2011. 


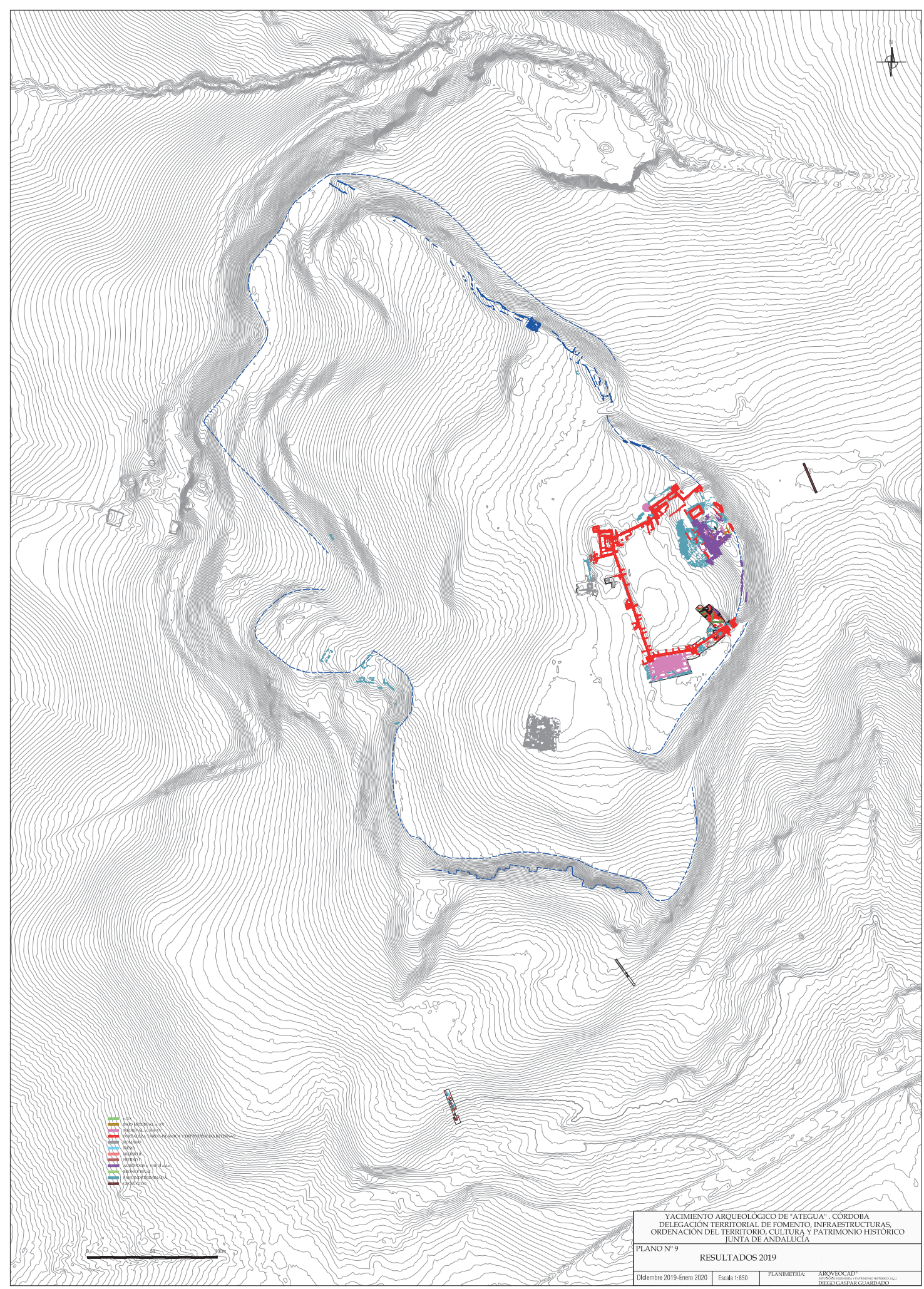

figura 4. yacimiento arqueológico de ategua. resultados a diciembre de 2019. (c) Enclave arqueológico de Ategua 


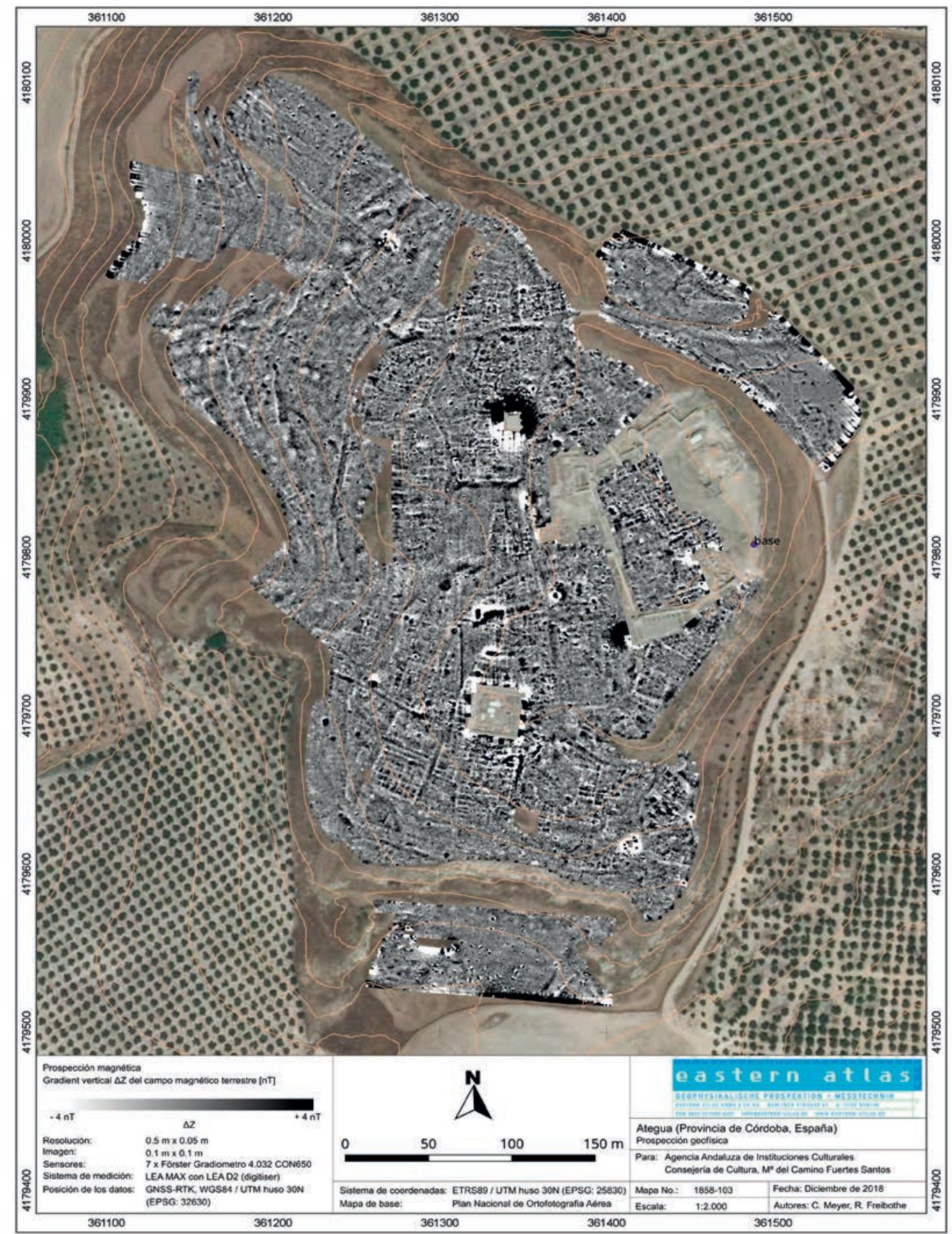

FIGURA 5. IMAGEN DEL ENCLAVE ARQUEOLÓGICO DE ATEGUA RESULTANTE DE LA PROSPECCIÓN MAGNÉTICA EN AMPLITUDES DE \pm 4 NT. (C) Consejería de Cultura y Patrimonio Histórico de la Junta de Andalucía (Fuertes y Meyer 2019: fig. 5) 


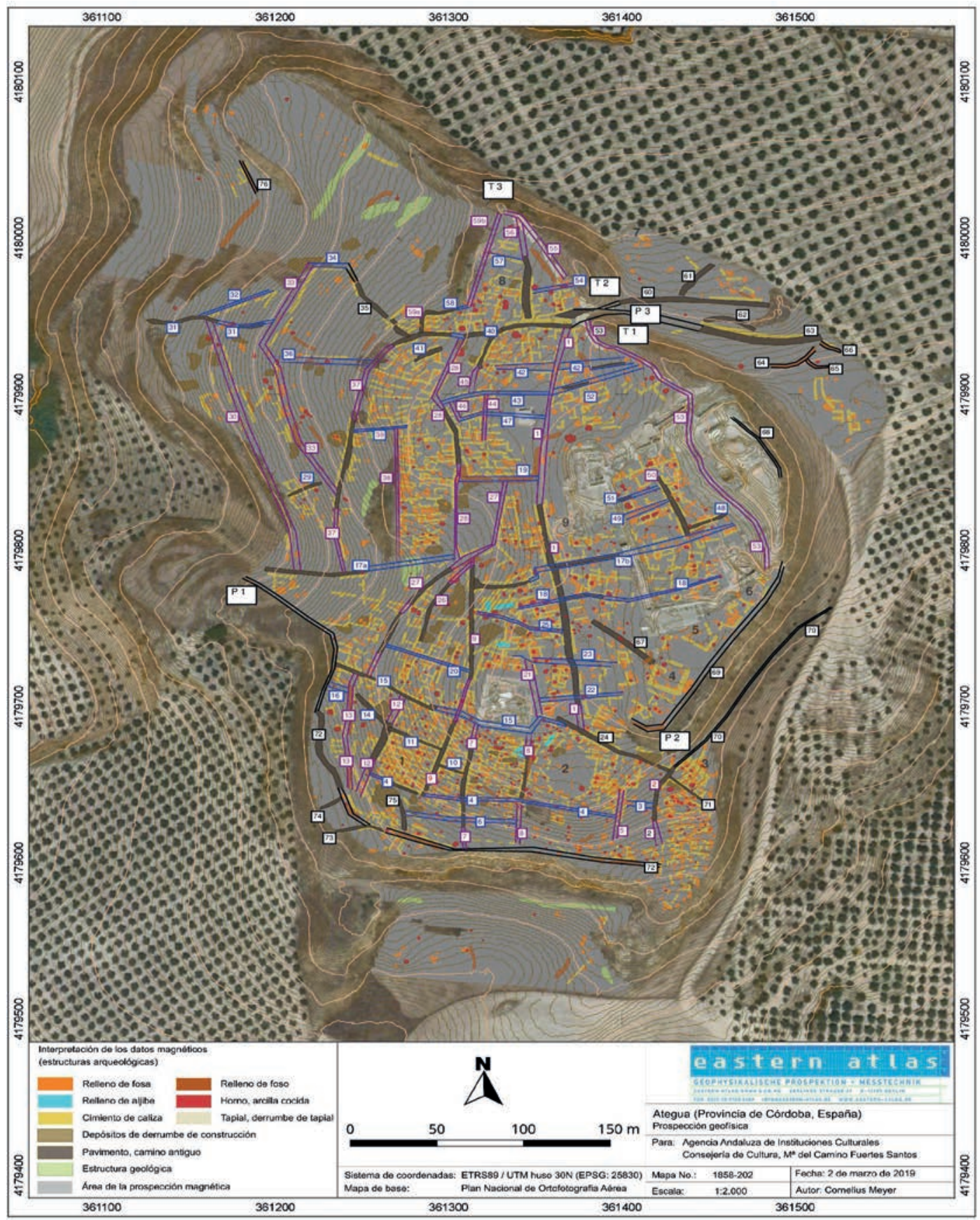

FIGURA 6. URBANISMO DEL INTERIOR DEL RECINTO AMURALLADO DE ATEGUA. IDENTIFICACIÓN DE MANZANAS Y SECTORES A PARTIR DE LA INTERPRETACIÓN DE LOS DATOS OBTENIDOS POR LA PROSPECCIÓN GEOFÍSICA (FUERTES Y MEYER 2019: FIG. 9) 
las primeras y su posterior victoria en la famosa batalla de Munda ${ }^{\text {r9 }}$. La relevancia de la ciudad romana ha quedado manifestada por los resultados conseguidos tras una prospección geofísica ${ }^{20}$ realizada al interior del recinto amurallado y que ha desvelado una urbe organizada en 76 calles que conforma un total de 59 manzanas en las que se agrupan edificios privados, comerciales y públicos - de los que ya se conocían unas termas, cuatro casas y un frente columnado de otra edificación pública- (figura 5). En esta prospección geofísica se han podido, incluso, observar cambios urbanísticos importantes que permiten intuir el proceso evolutivo de la ciudad en momentos anteriores y posteriores a su trazado hipodámico (Fuertes y Meyer 20I9). Dos excavaciones realizadas en 2020 con el fin de demostrar la fiabilidad de esta prospección, han sacado a la luz nuevas estancias de las termas y de una panadería en el ángulo noreste del cruce del cardo máximo con el decumano máximo (en la manzana 37$)^{21}$ y ratificar como edificio de espectáculos, tal vez el teatro ${ }^{22}$, el identificado con el número 2 por la prospección, en la manzana I $8^{23}$, (figura 6). Esta ciudad adquirió el estatus de municipio en época Flavia (Ventura 1994).

Por las fuentes escritas sabemos que en el siglo IV el presbítero Felicissimus, de la parroquia de Teba, acompañó al obispo cordobés Osio al concilio de Elvira. También conocemos la ubicación de una necrópolis cuyos materiales en superficie arrojan una cronología tardoantigua (Rodero 2007), aunque desconocemos, por el momento, el uso de la ciudad en esa época como tampoco sabemos nada de su uso durante el emirato. De la «Ataba» del siglo X no se ha localizado ninguna estructura arqueológica, si bien el Muqtabis de Ibn Hayyan nos cuenta que era una aldea perteneciente a la cora de Córdoba por lo que es de presuponer, al menos, que debió tener un pequeño núcleo poblacional. En el II65 las fuentes la citan ya como una aldea abandonada, noticia algo desconcertante puesto que del siglo XII es la fortaleza que se levanta en la zona más alta del cerro (Fuertes et al. 20II: I84 y

19. Una serie de anomalías observadas al exterior de la ciudad, en su lado occidental, nos inducen a pensar que nos encontramos ante las trincheras abiertas por las tropas cesarianas durante el conflicto del 45 a.d.e. (Fuertes y Márquez 2018) (figura 4).

20. Actividad arqueológica en la modalidad de documentación de yacimientos arqueológicos, para estudio geotécnico de los espacios identificados como plataforma superior y recinto protohistórico del E.A. Ategua. Directora de la intervención: Dña. Camino Fuertes Santos. Empresa especialista en prospecciones geofísica; EASTERN ATLAS. Dirección de los trabajos geofísicos: D. Cornelius Meyer. Topografía y planimetría. D. Diego Gaspar Guardado. Coordinadora del Enclave Arqueológico y de todos los trabajos: Dña. Camino Fuertes Santos.

21. Actuación Arqueológica Puntual en el posible espacio forense de la ciudad romana de Ategua: Termas y Foro. Enclave Arqueológico de Ategua, Córdoba. Director de la intervención: D. Juan de Dios Borrego de la Paz. Técnica en campo: Dña. Ana Felipe Colodrero. Dibujante Arqueológico: D. Diego Gaspar Guardado. Empresa Adjudicataria: Salsum S.L. Coordinadora del Enclave Arqueológico y de todos los trabajos: Dña. Camino Fuertes Santos.

22. Actividad arqueológica de excavación mediante sondeos correspondiente a la primera anualidad del Proyecto General de Investigación denominado: «Análisis urbanístico del yacimiento de Ategua: investigación arqueológica en el «edificio 1 - sector SE» (GRUPO PAI-HUM 882, UCO). Dirección de la intervención: D. Juan de Dios Borrego de la Paz. Técnicas de campo: Dña. Ana Felipe Colodrero y Dña. Isabel Gutiérrez Deza. Dibujo arqueológico: D. Massimo Gasparini y D. Juan Carlos Moreno Escribano. Director del Plan General de Investigación: D. Carlos Márquez Moreno. Arquitecto Técnico: D. Luis Olmedo Gordillo. Empresa adjudicataria: Arqueobética S.L Coordinadora del Enclave Arqueológico y de todos los trabajos: Dña. Camino Fuertes Santos.

23. Los niveles de abandono de la panadería y de las termas, bien constatados gracias a la presencia de materiales cerámicos en la estratigrafía, aseguran un abandono de ambos edificios en la primera mitad del siglo II d.n.e. No se han excavado niveles constructivos. En cuanto al edificio 2, su construcción se sitúa a finales del siglo I a.d.e. y se abandona el uso para el que fue construido en el siglo II d.n.e., siendo aprovechado el espacio desde ese momento hasta el siglo $\mathrm{V}$ de manera más precaria. La investigación de los tres edificios está en curso. 
ss.). Esta cerca, con nueve torres defensivas ${ }^{24} \mathrm{y}$ una del homenaje, se construyó sobre estructuras previas asociadas a materiales almorávides y/o almohades. Así mismo, son almohades las piezas cerámicas presentes en la base de la cimentación de la torre del homenaje (Fuertes 20I7, 58). Que la cerca es andalusí lo demuestra también su diseño adaptado a las medidas establecidas por el pie islámico $(3 \mathrm{I}, 43 \mathrm{~cm})$ y el codo mamuní (47,I4 cm). Aquel partía de un esquema cuadrado de 300 pies islámicos o 200 codos mamuníes con una anchura de 5 pies. Esta fortaleza fue reutilizada en etapas más recientes en las que se levantaron nuevas torres para defender los bastiones que defienden la puerta norte y el ángulo noroeste. Tres de ellas son de planta cuadrada, con técnicas edilicias similares, pero no idénticas, tal vez debido a que su construcción se llevó a cabo en diferentes momentos. La cuarta torre, la que se dispone junto a la puerta norte, de planta octogonal, es la más reciente. Su construcción permitió mejorar su defensa al convertir el antiguo acceso directo en uno acodado. Un mercado adosado al lado sur de esta fortaleza, otra serie de estructuras adosadas al interior de los lienzos sur y oeste de aquella y otras construidas en lo más alto de la fortaleza y de las que hablaremos más abajo, certifican el uso de este espacio en momentos finales de la Baja Edad Media (Fuertes et al. 20II: I92 y ss.).

De los momentos finales del uso de la ciudad se conocen dos noticias, ambas del siglo XV, en las que identifican el sitio como un lugar destinado a la explotación agrícola y al que se refieren como un espacio ya despoblado. La razón que condenó a la antigua ciudad debió estar relacionada con la señorialización de las vecinas villas de Espejo, Montemayor y Fernán Núñez ${ }^{25}$. Un dato estratigráfico que apoya esa fecha para el abandono de Ategua en algún momento indeterminado del siglo $\mathrm{XV}$ o de manera paulatina a lo largo de esa centuria, lo proporcionó una moneda localizada en un nivel de abandono sobre el que posteriormente se documentó el desplome del lienzo oeste del baluarte noroccidental de la fortaleza tardo-islámica. En la moneda, un cornado de vellón de Juan Il, se distingue en el anverso un busto mirando a la izquierda con corona y en el reverso un castillo. En la orla del anverso se puede leer + IOH [ANES DEI GR], en el reverso [IOHANES DEI] GR. La fecha de la moneda se establece hacia el segundo tercio del siglo XV lo que indicaría una cronología post-quem XV para el abandono del lugar en el que aparecióz ${ }^{26}$.

24. La del ángulo nororiental no ha sido excavada si bien se puede intuir su planta en el terreno.

25. Sobre este tema y sobre Ategua durante la etapa medieval, véase Córdoba 2005:102 y ss.

26. Entre $2007-2008$ se llevó a cabo una obra de consolidación de la fortaleza medieval que afectó a los niveles más modernos del yacimiento. Esta obra fue controlada por dos intervenciones arqueológicas. La primera de ellas dirigida por D. Fernando Penco y la segunda por Dña. $M^{a}$ José Asensi. De estas excavaciones solo se ha publicado, hasta el momento, el artículo correspondiente a los trabajos arqueológicos desarrollados durante esa anualidad (Asensi 2008). En el artículo no se recoge nada de relevancia que ayude completar el conocimiento sobre el uso de la fortaleza ni el final del poblamiento de Ategua. Sin embargo, en el informe administrativo depositado en la Delegación Territorial de Cultura y Patrimonio Histórico sí se recoge la secuencia estratigráfica de los cortes de esa intervención. La moneda se localizó en la UE 4 del Corte 12, en el Sector 2, de esa excavación. El Corte 12 de ese sector se abrió entre las dos torres que flanquean el baluarte noroeste de la fortaleza tardo-islámica (Vid.figura 7). Según esta arqueóloga, la unidad en la que aparece el cornado de Juan II se interpreta como un estrato de abandono bajo los de derrumbe de la muralla. El estudio de los materiales de la excavación dirigida por el Sr. Penco, anterior a esta otra, arroja una cronología post-quem siglo XIV para el abandono de las zonas excavadas que, en principio, hace extensible a toda la fortaleza (Penco et al. 2009). El cornado de vellón deja constancia del uso de algunas zonas un siglo más tarde. 
Tampoco podemos determinar cuándo se empezó a utilizar todo el actual espacio arqueológico como zona de labor. Lo que sí sabemos es que ese uso debió iniciarse ya durante el tiempo en el que la fortaleza tardo-islámica y el mercado bajomedieval aún aglutinaban a una población que, según los datos ofrecidos por las excavaciones más recientes, no parece extenderse mucho más allá de los muros de esa fortaleza ${ }^{27}$.

Durante el tiempo que se utilizó la zona como tierra de labor, el yacimiento fue utilizado para el enterramiento ilegal o alegal de entre io y I2 personas ${ }^{28}$. A excepción de una de ellas, el resto aparecieron en fosas comunes abiertas sobre niveles contemporáneos y modernos, sin ritual canónico de enterramiento y, algunas de ellas, con disposiciones anatómicas cuando menos sospechosas al no atenerse a la normativa habitual. Todo ello nos hace pensar que nos encontremos ante enterramientos clandestinos tal vez, tal y como ya apuntó en su momento su excavador, relacionados con la Guerra Civil española ${ }^{29}$.

\section{ESTADO DE CONSERVACIÓN DEL EDIFICIO}

Todos los edificios y estructuras excavados en los años 80 del pasado siglo presentaban a finales de esa centuria graves problemas de conservación que se fueron agravando hasta el inicio de su rehabilitación. Los trabajos realizados en 2007-2008, 2014, 2018-2019 y 2019-2020 (vid. notas IO-I2) se han centrado sobre los vestigios arquitectónicos excavados tanto en los años 8 o como en los anteriores a esta fecha y la razón para intervenir sobre ellos ha sido debida a la debilidad

27. Ni sobre los niveles de la panadería, ni sobre los del edificio de planta semicircular, posiblemente el teatro de la ciudad -identificado como Edificio 2- se ha documentado estratigrafía medieval ni moderna (Fuertes y Meyer 2019)

28. Las localizadas a día de hoy.

29. El estudio de los cadáveres se ha visto, por desgracia, salpicado por la controversia. La lectura con detenimiento de los cuadernos de campo de las excavaciones de los años 80 del pasado siglo, dirigidas por Martín Bueno y que en ellos se comentase la presencia de esos cadáveres, su posible relación -según sus excavadores- con la Guerra Civil, la claridad meridiana de que, al menos, varios de ellos están en una misma fosa, la fotografía de dos en la que es perfectamente apreciable que ambos cuerpos están en posición dispar lejos de las normas canónicas de enterramiento, el recuerdo de los entonces colaboradores de esas excavaciones y hoy catedráticos D. Enrique Aguilar (UCO) y D. José Luis Jiménez (UV) de la aparición de al menos una insignia militar (tal vez todavía en las cajas del Museo Arqueológico de Córdoba) y de su recuerdo sobre la reacción de los operarios (vecinos de Santa Cruz, el pueblo más cercano al yacimiento) ante la presencia de los mismos y sus comentarios haciendo alusión a la posibilidad de que se tratase de víctimas de esa guerra y de que pudieran ser sus parientes, supusieron indicios suficientes como para considerar la posibilidad de que estos cadáveres estuvieran relacionados con ese episodio bélico y por lo tanto se considerase oportuno proceder a llevar a cabo un estudio en profundidad de los mismos. Con todas estas premisas, la coordinadora del sitio y una de las autoras de este trabajo, solicitó la búsqueda de los restos óseos en las cajas en las que estaban almacenados los materiales derivados de las excavaciones. El permiso fue concedido y se certificó su presencia. A partir de aquí, se solicitó un informe forense de los cadáveres con el fin de conocer cuánto pudieran aportar. La Dirección General de Memoria Histórica del momento (2017-2018) encargó un estudio preliminar de los restos que adjudicó directamente al arqueólogo Guijo Mauri, especializado en arqueología forense. El arqueólogo suscribió un informe plagado de errores de bulto, en el que se atrevió a certificar que los restos humanos no lo eran de personas relacionadas con ese hecho bélico. La coordinadora del sitio presentó una memoria ante la Delegación Territorial de Cultura, ante la Dirección General de Memoria Democrática en ese momento dependiente de la anterior Consejería de Presidencia y ante la Dirección General de Bienes Culturales, en la que ponía de manifiesto todas y cada una de las inexactitudes relacionadas por el Sr. Guijo y solicitando un nuevo estudio forense metodológicamente correcto. El asunto ha sido aparcado hasta el momento. La documentación puede ser consultada en las distintas administraciones autonómicas en las que ha sido presentada. 
que presentaban las estructuras a causa de su antigüedad, de su exposición a las inclemencias meteorológicas y a la presión que sobre las estructuras excavadas ejercían las tierras dispuestas en su posición estratigráfica (figura 7).

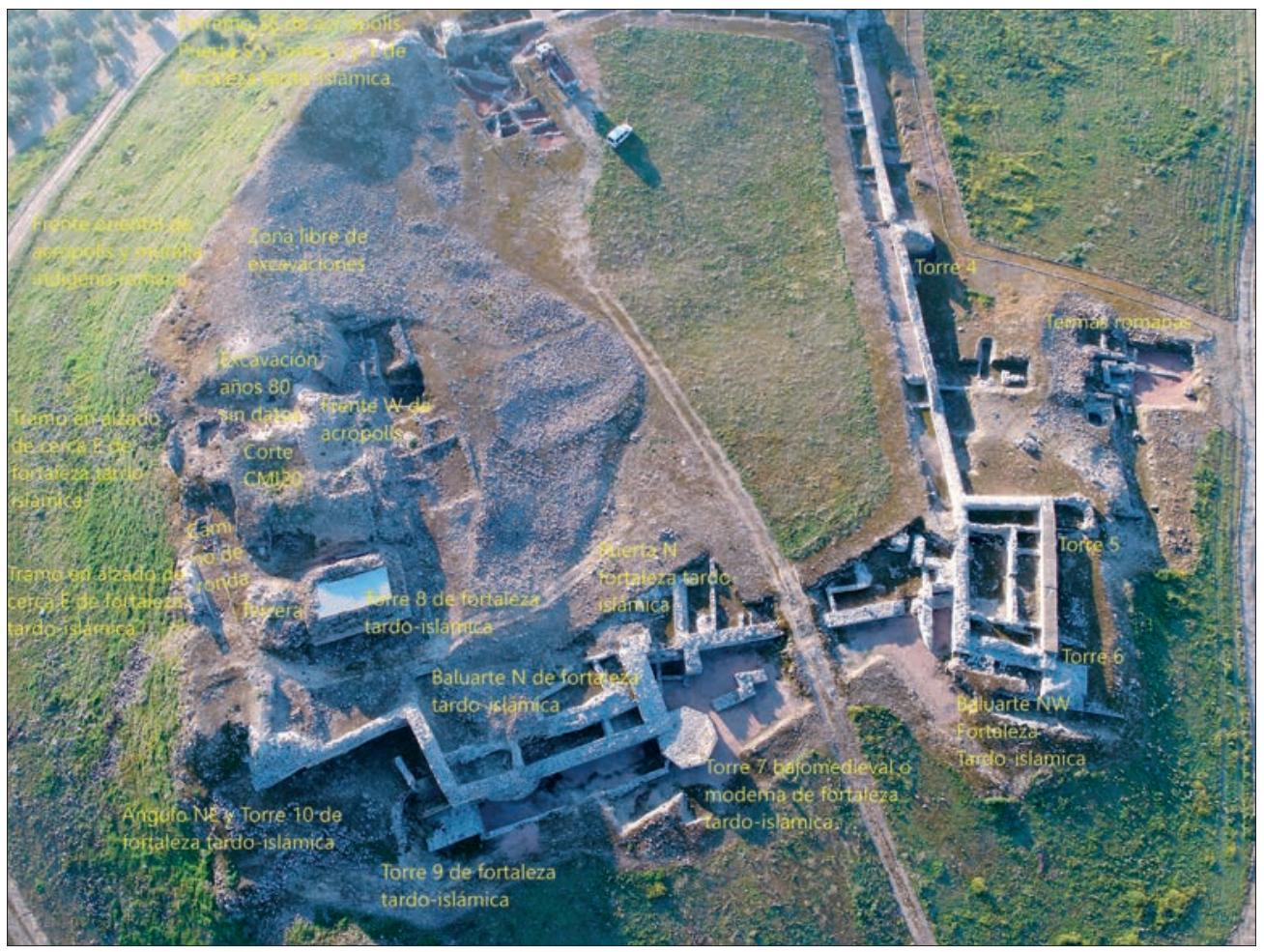

FIGURA 7. CUMBRE DE LA ACRÓPOLIS Y FRENTE NORTE DE LA FORTALEZA TARDO-ISLÁMICA CON IDENTIFICACIÓN DE ESPACIOS Y ESTRUCTURAS. (C) Interpretación M. ${ }^{a}$ C. Fuertes sobre fotografía de A. López

La primera actuación sobre la acrópolis se efectuó en 2014 sobre el paramento medieval interpretado por Blanco en los años 60 del siglo $\mathrm{XX}^{3}$. En este caso y a la vista de la ausencia de documentación del mismo, se hizo un levantamiento planimétrico de detalle antes de comenzar la obra de restauración con el fin de obtener una imagen real de este muro antes de aquella. Del paramento en cuestión sabemos que, sobre una obra de mampostería de características similares a las del lado occidental de la acrópolis, se levanta un cajón de tapial cuya longitud máxima conservada -en la base de unión con el alzado de mampuesto- es de $5 \mathrm{~m}$ y cuyo estado de conservación era pésimo, por lo que corría riesgo real de desplomarse. Para evitar su derrumbe se recalzó con ladrillo y con nuevo tapial ${ }^{31}$.

Los trabajos de consolidación de la cara oeste de la acrópolis se llevaron a cabo en dos campañas realizadas en 2018-2019 y en 2019-2020 (figura I). Las estructuras se encontraban muy debilitadas tras su exposición al aire libre y al empuje de tierras

30. Vid. nota 12 .

31. La obra nueva de ladrillo ha quedado conservada detrás de un nuevo paramento levantado con el mampuesto de la antigua obra caída consolidado con una mezcla de cal y arena. La obra vieja se ha separado de la nueva con malla y geotextil. El tapial original se ha consolidado con una mezcla de agua con cal (figura 14.2). 
del interior del núcleo del edificio durante un tiempo prolongado, habiendo resultado dañados los muros de contención, que presentaban derrumbes parciales. Las patologías y desperfectos observados han sido debidos al deterioro causado por los agentes meteorológicos sobre estructuras descubiertas. El estado de conservación era muy deficiente, los derrumbes alcanzaban a gran parte de las estructuras, habiéndose perdido tramos de los paños de fábrica debido a la caída de los mampuestos y amenazaban con avanzar con rapidez ya que los muros-cajón habían dejado de trabajar como un conjunto y sus bordes estaban debilitados. Como consecuencia de los desplomes, los perfiles presentaban una gran inestabilidad al haberse quedado al descubierto. A causa de todo ello, en las zonas de meseta del edificio se acumulaba tierra derivada de los derrumbes. Los daños se acentuaban debido al problema de la acumulación de agua en los cortes abiertos en la cumbre de la acrópolis que habían dejado al descubierto el núcleo del edificio y de los se había retirado gran parte de la estratigrafía relacionada con su evolución histórica. El agua se acumulaba en las cotas superiores y su filtración hacia el interior ejercía presión hacia el exterior, sobre las estructuras. Los daños se acentuaban debido a la gran presencia de madrigueras en el subsuelo que lo convertían en inestable a la acción del peso.

Con el fin de paliar los daños se han llevado a cabo tareas de limpieza, retiradas de tierra y de derrumbes. Se han rejuntado las fábricas con mortero de cal hidráulica ${ }^{32}$ para aumentar su resistencia a la compresión y flexo-tracción. Se ha rehundido la junta de mortero para no alterar el aspecto de las fábricas. Para frenar el avance del deterioro, se han adoptado medidas que garantizan una mayor protección frente a los agentes atmosféricos: se han acabado las caras superiores de los muros para garantizar la evacuación de las aguas pluviales y se han conducido las aguas hasta un lugar en el que no puedan producir daños a estructuras descubiertas $\mathrm{u}$ ocultas en el subsuelo. Se han consolidado las estructuras deterioradas, limpiando y retacando las juntas con mortero de cal hidráulica. Se han completado los paños de fábrica de mampostería ejecutando refuerzos de fábrica en aquellos tramos colapsados, mientras que las caras superiores de los muros han sido acabadas de manera que se facilite la evacuación del agua. El rejuntado de frente de fábricas de mampostería se ha realizado con mortero de cal hidráulica y arena de río previa limpieza de juntas con cepillo de raíces. En los casos que ha sido necesario recalzar los muros de cantería, se han levantado muros de mampostería con fábrica de ladrillo de tejar armada con fibra de vidrio, previa compactación del terreno por medios manuales. Los lienzos de fábrica de mampostería ordinaria de piedra biocalcarenita se han ejecutado manteniendo el aparejo, pero con mampuestos de tamaño ligeramente mayor al de los existentes, con objeto de diferenciarlos de la fábrica original. Mediante tiras de plomo se han separado las caras vistas de la obra original de la restaurada. La obra interior restaurada se separa de la original por medio de tiras de malla plástica de color azul. Se han puesto placas donde se indica la palabra «Restauración» y el año de la misma.

32. Se han realizado muestras de color del mortero para que se altere lo menos posible la visión general del edificio. 
Para evitar la acumulación del agua en los cortes de la cumbre y su posterior filtración hacia el interior del edificio se ha ejecutado un relleno con material granular hasta alcanzar una cota que permitiese proteger la depresión en su totalidad y se ha instalado un desagüe que vierte las pluviales de la depresión superior hasta el suelo del yacimiento.

Una vez liberada la obra original de los derrumbes se levantaron los paramentos en las lagunas dejadas por ellos, de manera similar a la obra original. Ambas obras han quedado separadas por malla plástica de color azul y las caras exteriores por láminas de plomo. Para rehacer los muros caídos se han levantado en primer lugar las caras de los paramentos, con hileras de mampuesto manteniendo la horizontal, siguiendo la inclinación original de los taludes y, en segundo lugar, el interior se ha rellenado con piedra, de la misma manera que en la obra original con el fin de otorgarle la máxima solidez.

\section{ZONAS DE ACTUACIÓN.}

\subsection{FRENTE OESTE DE LA ACRÓPOLIS (figura 8)}

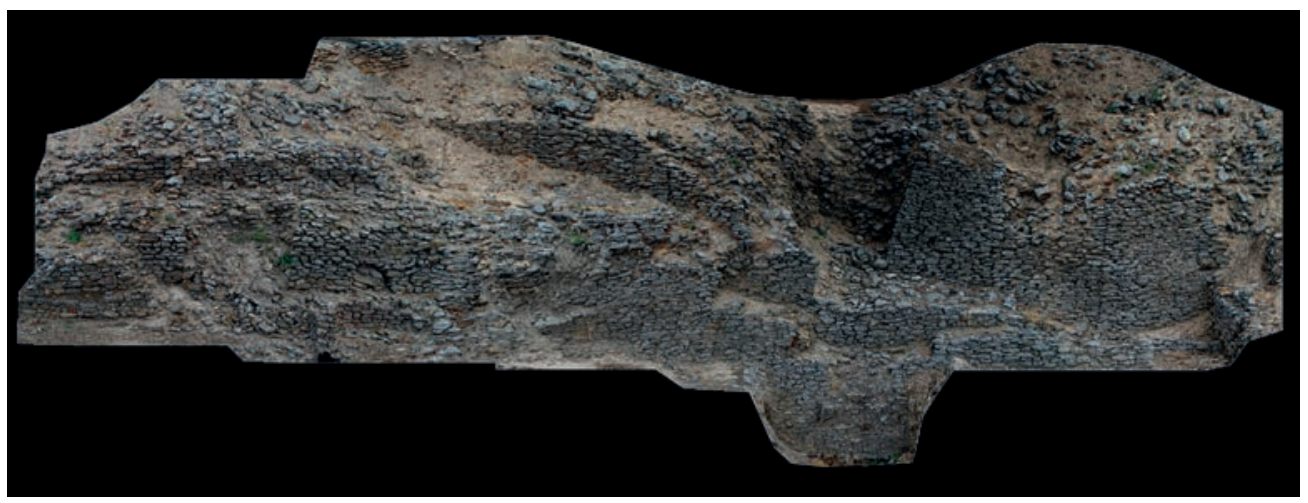

Figura 8. ORTOFOTO DEL FRENTE OESTE DE LA ACRÓPOLIS ANTES DE COMENZAR LOS TRABAJOS DE CONSOLIDACIÓN. (C) Enclave arqueológico de Ategua. Imagen montada por Arqueocad S.L.

Las intervenciones arqueológicas de más calado son aquellas que han afectado a las zonas derrumbadas que afectaban a rellenos arqueológicos en posición original cuya excavación ha permitido arrojar luz sobre la cronología y uso del edifico ${ }^{33}$.

\section{Actuaciones sobre los cajones 2, 8, 9, 10, 11, 12, 15 y 18 (vid. Figura 3)}

Los trabajos de conservación de más calado se concentraron en cuatro zonas en las que las caras de los muros del talud estaban parcialmente derrumbadas,

33. Durante la obra de 2018-2019 se llevó a cabo la primera actuación de consolidación de la cara oeste de la Acrópolis que fue finalizada en 2019-2020 cuando, además, se actuó sobre los cortes abiertos en la cumbre del edificio y en su lado norte (Borrego 2019). 
afectando a los cajones 2, 8, 9 y I5 $5^{34}$ (figura 9). Las paredes caídas dejaron a la vista el núcleo del edificio, formado por rellenos de piedra dispuestos de manera aleatoria, compactados con margas. En ningún caso se ha apreciado el uso de la cal para llevar a cabo la obra35.
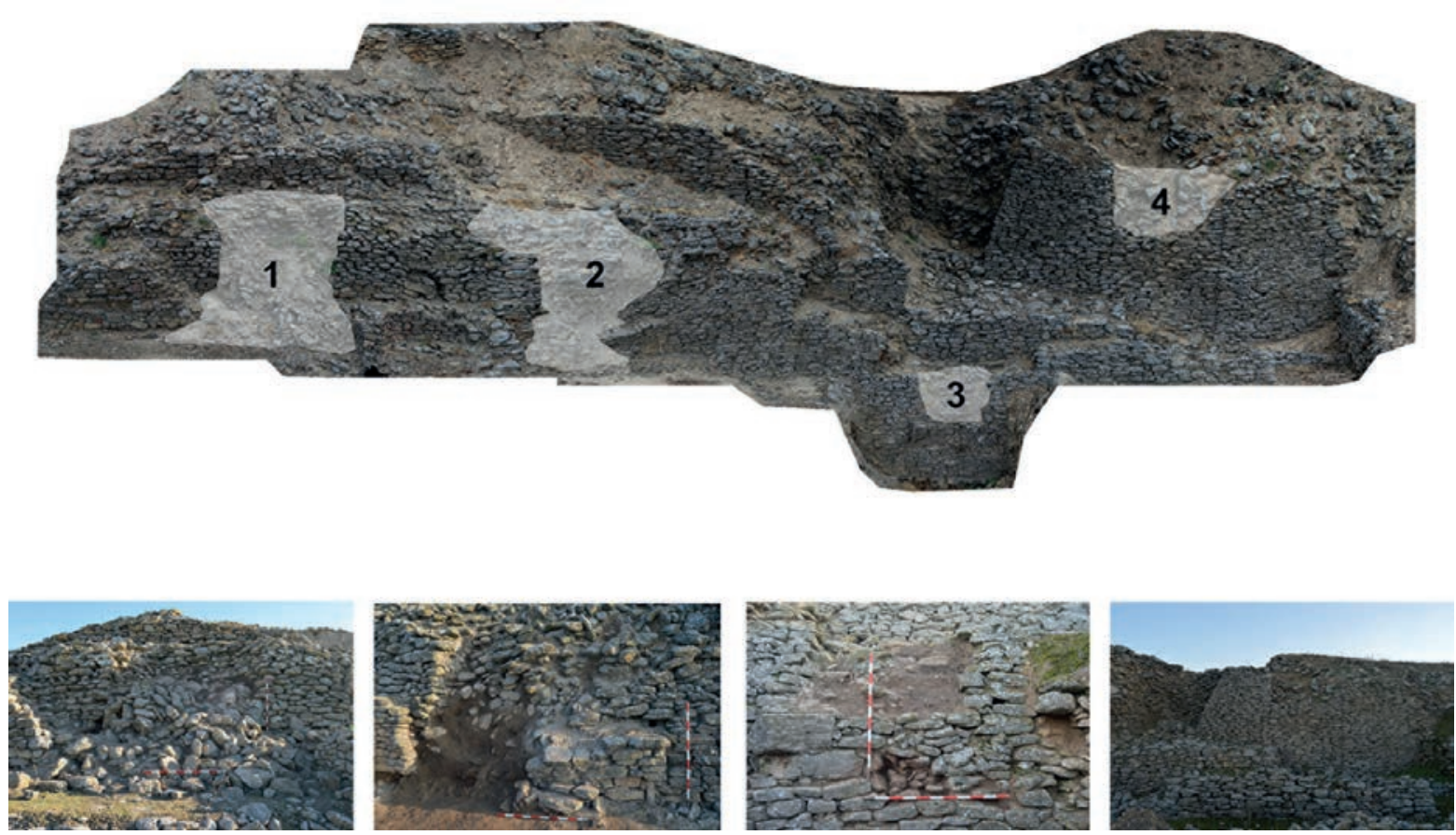

FIGURA 9. SOBRE ORTOFOTO DEL FRENTE OESTE DE LA ACRÓPOLIS, LOCALIZACIÓN DE LAS ZONAS DERRUMBADAS EN LOS CAJONES 2 (DERRUMBE 4), 8 (DERRUMBE 3), 9 (DERRUMBE 2) Y 15 (DERRUMBE 1). ABAJO FOtografía de CAdA derRumbe bajo su SEÑALIZACIÓn EN LA ORTOFOTO. C) J. D. Borrego (2018, fig. 11)

La cerámica recogida en los derrumbes ya colapsados de la acrópolis se correspondía con diferentes producciones de distintas etapas históricas, desde época medieval hasta época ibérica. La presencia de una bola de catapulta de medio pie romano de diámetro en el derrumbe del cajón $\mathrm{I}^{5^{36}}$, de cerámica andalusí almohade en el relleno interno que cubría el muro de contención del cajón $9^{37 y}$ de paramentos de refuerzo posteriores a la obra original, como el observado en ese cajón 9, certifica la reparación del edificio y su uso continuado a lo largo de la historia.

El cajón 8 es el perfil oriental del corte denominado CM Gi6, excavado en los años 80 del pasado siglo (figura 3). Durante su excavación se alcanzaron niveles protohistóricos, si bien la reinterpretación de los datos de la intervención arqueológica solo ha permitido determinar tres fases de ocupación. La más moderna

34. En la obra de 2018-2019 los derrumbes fueron numerados de 1 a 4 desde el norte al sur. El 1 afectaba al cajón 15, el 2 al cajón 9, el 3 al cajón 8 y el 4 al cajón 2. (Fuertes 2017: figuras 5 y 25; Borrego 2019)

35. La obra de conservación llevada a cabo sobre el derrumbe del cajón 2 -denominado derrumbe 4 durante el proceso de excavación- no ofreció datos de interés arqueológico.

36. Derrumbe 1 según informe de control arqueológico (Borrego 2019).

37. Derrumbe 2 según informe de control arqueológico (idem). 


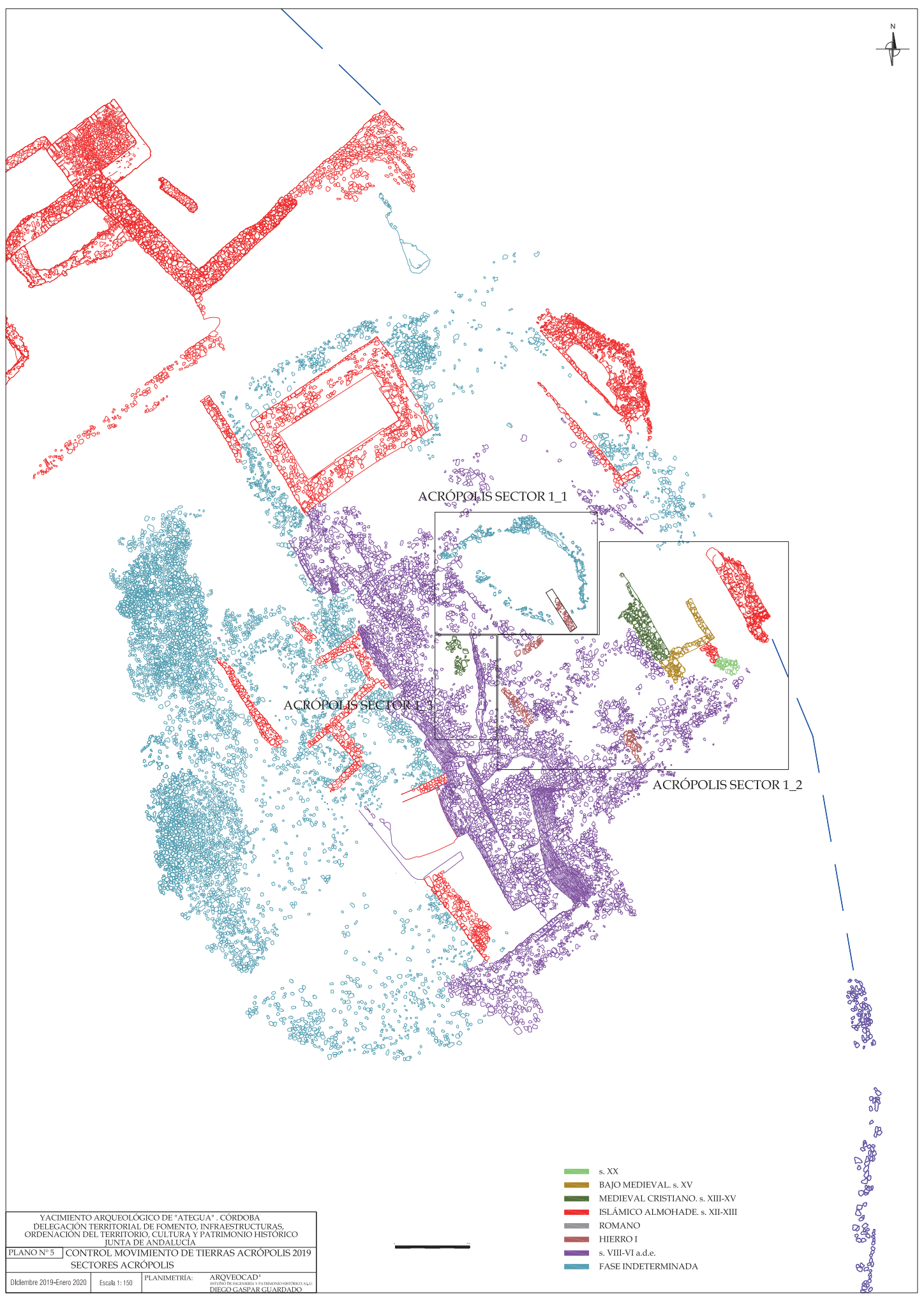

FIGURA 10. ACTUACIÓN 2019-2020. DIFERENCIACIÓN POR SECTORES. @ Enclave arqueológico de Ategua 
de época medieval, en la que se localizó un espacio que tal vez formó parte de la organización interna de la fortaleza tardo-islámica. Los materiales medievales parecen andalusíes tardíos -siglo XII- si bien es muy posible que un estudio detallado de los mismos ofrezca una cronología más moderna. De este momento pueden ser los dos paramentos localizados en los perfiles norte y sur del corte y que aún son visibles. Bajo los niveles medievales y sin solución de continuidad parecen disponerse otros, de época ibera -según sus excavadores- asociados a una construcción con adobes que de alguna manera estuvo vinculada a la cara oeste de la acrópolis, en donde se localizaron 5 pondera por lo que, tal vez, se pudiera prever la presencia de un telar y en donde, según se recoge en las anotaciones de campo, se localizó la bóveda de un horno de ese momento ${ }^{38}$. La tercera fase en un primer momento pensamos que estaría asociada a un momento indeterminado de la etapa del Hierro, pensando que, tal vez, la zanja de cimentación de la acrópolis había afectado a esa edificación ibera. Propusimos por tanto que la acrópolis se había construido abriendo, para llevar a cabo su cimentación, una zanja que afectaba ese espacio ibero, en donde pudo haber estado instalado un telar, y a niveles más antiguos de los que se habían recuperado materiales del Bronce Final (Fuertes 2017). Sin embargo, en la obra de 2018 que afectó y consolidó los muros de este corte y que permitió limpiar los perfiles abiertos en los años 8o, no se ha podido apreciar, en los rellenos sedimentarios aún conservados, ninguna zanja de cimentación, lo que indicaría que los niveles iberos se adosarían o estarían relacionados con la cara oeste. En este corte la acrópolis parece elevarse directamente sobre una superficie sedimentaria que suponemos más o menos horizontal de la que se recuperaron 8 fragmentos de cerámica, en concreto seis galbos de cerámica engobada y espatulada y dos bordes de cerámica gris, cuya cronología podría encuadrarse entre los siglos VII-VI a.d.e. (figura Io) ${ }^{39}$.

Por otro lado, fue necesario actuar sobre los cajones io, in y i2, con la idea de además de consolidar la obra -que no estaba derrumbada- de proceder a la retirada de niveles de sedimento y derrumbes de piedras, procedentes de la zona más alta, que se acumulaban sobre ellos

Estos cajones se caracterizan por presentar una técnica edilicia ligeramente distinta a la vista en el resto de los observados en la cara oeste de la acrópolis y es que los mampuestos que levantan las caras vistas son más largos que altos. Además, estos tres tramos murarios, no mantienen la dirección norte-sur que se observa en el resto de los excavados, sino que aquella es suroeste-noreste. La razón de esta orientación no sabemos interpretarla, por el momento.

La intervención arqueológica afectó por una parte a los rellenos caídos sobre las estructuras, a los muros de los cajones y, más escasamente, al relleno interior de los mismos. Los rellenos derivados de la caída de los niveles sedimentarios

38. De la misma no hemos visto nada en esta nueva intervención.

39. Estos materiales han sido recuperados en 2018 al decidirse en obra que la pared ataluzada de la acrópolis documentada en este corte fuera calzada con un muro de ladrillo, pues las excavaciones llevadas a cabo en los años 80 habían rebajado parte del nivel sedimentario sobre el que se apoyaba, dejando un tramo de $5 \mathrm{~m}$ de pared descolgado. Para la colocación de los ladrillos fue necesario perfilar el sedimento sobre el que se asentaba que es sobre el que se levanta la acrópolis en este tramo. 
superiores contenían fragmentos cerámicos de un arco temporal que abarcaba desde la protohistoria hasta la Edad Media dispuestos sobre un antiguo derrumbe de los cajones Io, II y I2, con material cerámico - galbos- pintado a bandas, cerámica fabricada a mano y cerámica a torno gris, por lo que el estrato fue fechado, con reservas por el momento, en Hierro I (siglo VIll a.d.e). De la misma cronología, por tanto, sería el relleno que soportaban las caras de los cajones io, il y i2 y la construcción de los mismos ${ }^{40}$.

\subsection{CUMBRE DE LA ACRÓPOLIS (figura 7 y figura io)}

Del único corte abierto en esta zona del que tenemos noticias de su excavación es del identificado, en I983, como CM I20 (Fuertes 20I7: plano 6).

Según el cuaderno de campo de ese año sabemos que se retiraron I,5 $\mathrm{m}$ de estratigrafía sin separación estratigráfica ni por niveles artificiales, ni naturales. Del relleno excavado se recuperaron materiales de cronología ibera y bajo el mismo se localizó una alineación de piedras sueltas asociada a un nivel sedimentario de color rojizo con restos de adobe y una capa de cenizas de poco espesor. La cerámica recuperada de esos dos niveles era: campaniense A, ibérica, Hierro I, de tradición púnica y bruñida. A día de hoy no son visibles esos adobes, no sabemos si fueron retirados o si, simplemente, han desaparecido tras el transcurso de los 35 años que separan su excavación de la nueva actuación.

En el espacio que ocupaba ese corte antiguo se detecta, en su perfil oeste, en el borde del mismo y por tanto en línea con el resto de los cajones que conforman la pared occidental de la acrópolis, un paramento del que son visibles $1,5 \mathrm{~m}$ de longitud, con una altura conservada de $0,5 \mathrm{~m}$. Este muro, construido con mampuestos alineados del que se conservan 7 hiladas, se ha considerado como parte de lo que pudo ser el muro-cajón I8, el que se alzaría en lo más alto de la cumbre. Tal vez, por otra parte, pudo ser uno de los paramentos de algún edificio que estuviera en esa zona instalado y cuya estratigrafía fue eliminada durante su descubrimiento. Con el fin de evitar que el muro se desplomase, fue necesario replantear el perfil sedimentario inferior a la primera hilada de mampuestos conservada y, de esta manera, conseguir una superficie horizontal para la introducción de ladrillos que sostuvieran la obra antigua ${ }^{41}$. Se actuó sobre un espacio de 0,6 m de longitud, o,2 $\mathrm{m}$ de altura y entre 0,I0 y 0,15 $\mathrm{m}$ de anchura. En ese breve espacio sedimentario fueron detectadas tres unidades estratigráficas, de las que solo se recuperó material diagnosticable en las dos más inferiores, concretamente varios fragmentos de cerámica cuya cronología apunta a finales del siglo VIII-VI a.d.e ${ }^{42}$ (figura 11).

40. UUEE o-2 serían los niveles superiores y que cubren al derrumbe de las caras de los cajones (UE 3) así como a ellos (U.E. 4) y a su relleno interno (U.E. 5) según informe arqueológico preliminar depositado en la Delegación Territorial de Cultura y Patrimonio Histórico por la directora de la excavación Dña. I. Carrasco.

41. Intervención identificada en 2018-2019 como «muro superior» (Borrego 2019).

42. Desde aquí queremos agradecer a D. Juan F. Murillo Redondo su ayuda a la hora de analizar, tipificar y fechar esa cerámica. 

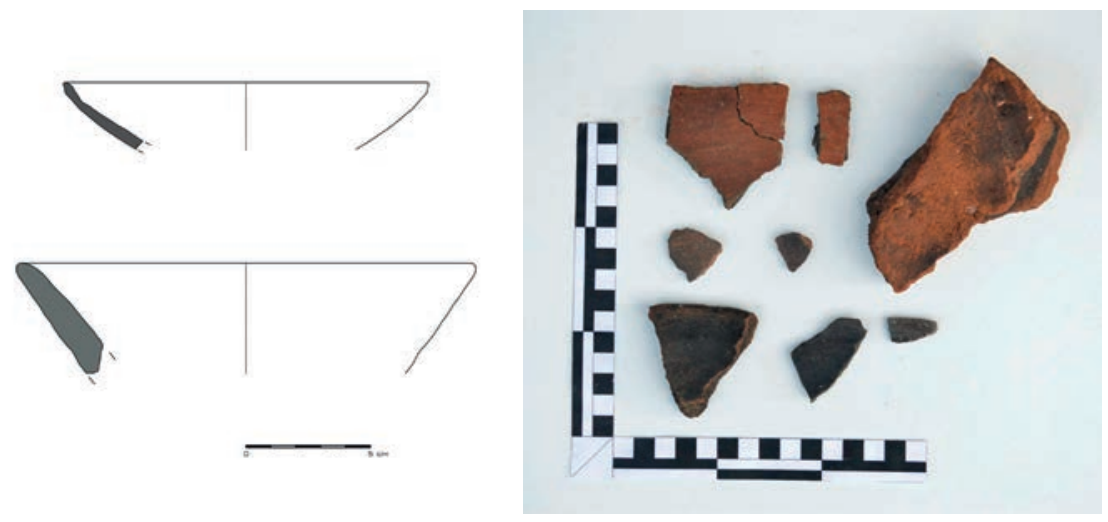

Conjunto de materiales de la U.E. 46 del corte CMG16.
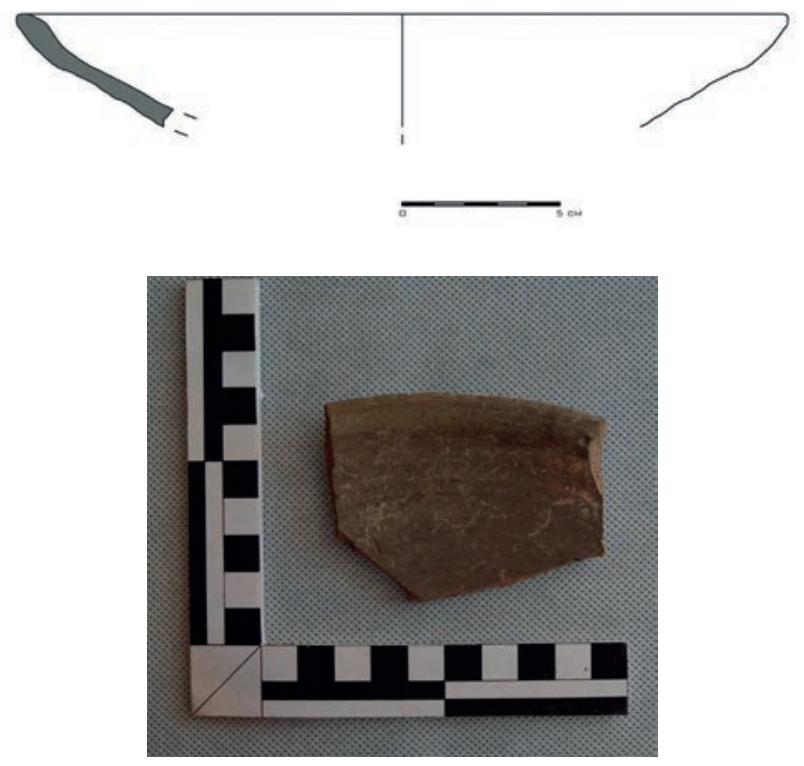

Cuenco de cerámica gris recuperado bajo la primera hilada del muro-cajón

FIGURA 11. ARRIBA: CONJUNTO DE MATERIALES DE LA UE 46 DEL CORTE CM GI6 (INTERVENCIÓN DE 2OI8) RECUPERADOS EN ESE SEDIMENTO SOBRE EL QUE SE LEVANTA EL MURO-CAJÓN 8. ABAJO: CUENCO DE CERÁMICA GRIS RECUPERADO BAJO LA PRIMERA HILADA DEL MURO-CAJÓN 18 (INTERVENCIÓN DE 2OI8). (C) J. D. Borrego (2018)

Además de este paramento, es llamativa la presencia en ese corte de un mortero de cal cuya presencia se observa, también, en otros puntos de la parte más alta de la acrópolis. Este mortero, en principio de apariencia similar al opus caementicium y del que hablaremos más abajo, se asienta, en este corte, sobre los rellenos de mampuesto que constituyen el núcleo del edificio protohistórico y sobre los niveles sedimentarios que los cubre. No contamos con datos para determinar su cronología ${ }^{43}$.

43. Sector 1_1 de la figura 11. En color azul claro (color que indica cronología indeterminada). 
Tanto este mortero, como el núcleo del edificio protohistórico, formado por mampuestos de calcarenita, dispuestos verticalmente y unidos con margas, estaban cubiertos y afectados por las obras de excavación realizadas durante los años $8 \mathrm{O}^{44}$.

$\mathrm{Al}$ sur del corte CM I2O es perfectamente apreciable un rebaje de terreno, en dirección este-oeste, que afectó a toda la cumbre de la acrópolis en unos dos metros de profundidad (figura I2.I). Este rebaje ocupó de alrededor de Ioo $\mathrm{m}^{2}$, superficie cercana a la de 3 cortes arqueológicos de $5 \times 6 \mathrm{~m}$. De aquellas excavaciones no contamos con ningún tipo de documentación y lo único existente es lo que no fue retirado ${ }^{45}$.

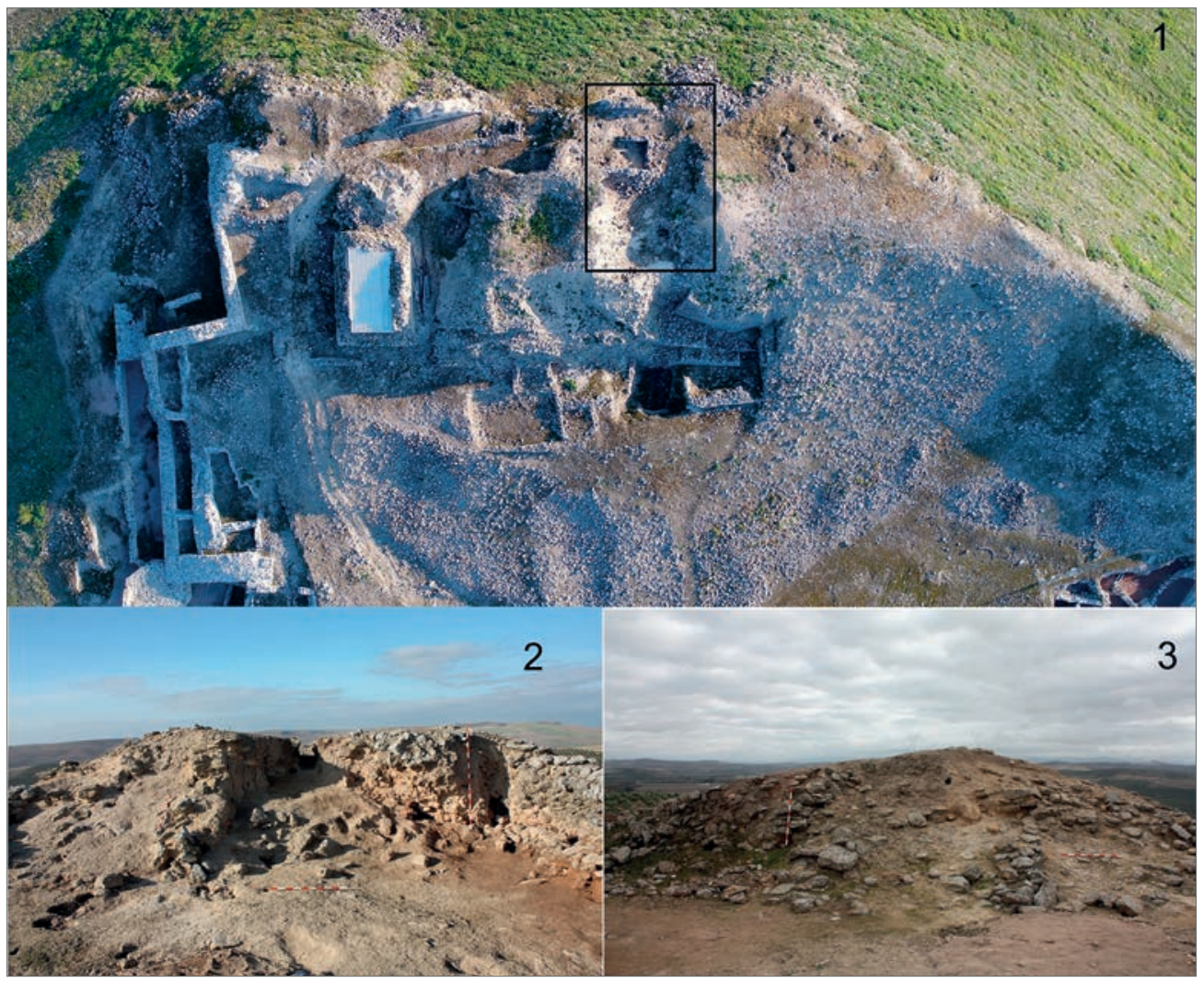

FIGURA 12. 1. VISTA CENITAL DE LA CUMBRE DE LA ACRÓPOLIS. AÑO 2017. EN LA ZONA SEÑALADA ZONA EXCAVADA SIN DATOS.

(C) Modificación sobre fotografía A. López. 2. Perfil N del Sector 1_2 de la cumbre de la acrópolis.

(c) I. Carrasco. 3. Perfil S del Sector 1_2 de la cumbre de la acrópolis. (C) I. Carrasco

44. Con el fin de evitar la acumulación de agua en esta zona y sobre todo con el fin de evitar que aquella dañara el interior del edificio y lo debilitara, entre otras actuaciones de impermeabilización, se abrió una zanja, de 2,95 m de longitud y 0,5 m de anchura, con una pendiente del $2 \%$ dirigida hacia el sur en la que se instaló una tubería cuyo trazado completo canaliza las aguas hacia la pendiente oriental de la acrópolis. Los niveles excavados están todos relacionados con la intervención arqueológica de los años 80 del pasado siglo. No se llegó a tocar ningún nivel original. Antes de comenzar siquiera la excavación de la zanja se tomó contacto con lo excavado en los años 80 del siglo XX y se observó la presencia de materiales cerámicos de cronologías de todos los momentos constatados en la acrópolis, desde el medioevo hasta el Hierro I (Carrasco 2019) (figura 11).

45. Sobre este espacio se ha llevado a cabo una intervención destinada a la consolidación de estructuras y perfiles, a la impermeabilización del núcleo de la acrópolis y a la canalización de las aguas pluviales (figura 11). Durante la obra 2019-2020 esta zona fue identificada como Sector 1_2 (idem). 
Por el momento y a la espera de una intervención arqueológica más ambiciosa en esta zona, lo datos con los que contamos son los siguientes:

\subsubsection{Perfil norte. De oeste a este (Figura io y figura 12.2)}

* Sedimento arcilloso en parte derrumbado.

* Muro de dirección norte-sur, de cinco hiladas de mampuesto que se ha quedado cortado en el perfil (desconocemos si transcurría por el corte abierto). El muro se levanta sobre un nivel sedimentario previo.

* Perfil sedimentario con numerosas piedras.

* Gran bloque informe de piedra/piedras y tierra de color rojizo, color tal vez derivado de una exposición prolongada al fuego y que es perfectamente distinguible del resto de materiales inorgánicos existentes en el yacimiento, con un buzamiento muy acusado oeste-este, cubierto por restos de mampuesto de calcarenita y de un mortero de cal que se extiende por toda la cumbre (el mismo observado en el corte CM I20 con el que linda este perfil -vid. supra- ${ }^{46}$. Este bloque está afectado por la zanja de cimentación del paramento de «espina de pez», muro occidental del camino de ronda de la fortaleza tardo-islámica (vid. a continuación).

\subsubsection{A continuación del perfil norte. De oeste a este (Figura ro y I3)}

* Paramento de «espina de pez» de dirección norte-sur ${ }^{47}$ (figura 13.I). Su construcción afectó al bloque de piedra de color rojizo al que antes hemos hecho alusión e, igualmente, al mortero que sobre el mismo ocupa el borde de la cumbre. Este muro fue trabado directamente sobre lo que hubiera con anterioridad a él, y debió actuar como muro occidental del camino de ronda de la fortaleza tardoislámica y bajo medieval y a su vez, como muro de contención de los empujes de las tierras y piedras del edificio protohistórico y de las estructuras posteriores al mismo. Por su lado oeste, el muro estaba en parte derrumbado y del mismo ha quedado a la vista su núcleo. Sí se conserva la cara oriental para la que se utilizó un aparejo en espiga o en «espina de pez», alternando con mampuestos alineados horizontalmente. Del paramento son visibles alrededor de 6,3 $\mathrm{m}$ de longitud, conserva una altura de I,5 $\mathrm{m}$ de mampuestos distribuidos en II hiladas conservadas en su zona más alta. Se adentra en un área no excavada al norte. La cronología de este paramento es tardo-islámica o bajomedieval, anterior, seguramente, al siglo XV. En su extremo sur otro muro, de peor factura, también

46. U E 7 del Sector 1_2 según informe preliminar de esta intervención depositado en la Delegación Territorial de Cultura y Patrimonio Histórico firmado por la directora de la misma Dña. I. Carrasco (figura 11).

47. UE 3 del Sector 1_2 según informe preliminar de esta intervención depositado en la Delegación Territorial de Cultura y Patrimonio Histórico firmado por la directora de la misma Dña. I. Carrasco (figura 11). 
de mampuesto de calcarenita, continua su trazado hacia esa dirección. Del mismo solo se conservan 4 hiladas (figura io).

* Al anterior paramento se le entrega otro, de dirección este-oeste ${ }^{48}$ con un vano de acceso en el ángulo que forma con aquel (figura I3.2) y que junto con un tercero ${ }^{49}$, de dirección norte-sur (figura I3.3), parecen conformar un pequeño espacio de habitación. La cronología de esta habitación es posterior a la construcción del muro de «espina de pez».

* Estructura de dirección norte-sur que se adosa al muro este del espacio descrito más arriba y que, tal vez, formó parte de algún espacio del camino de ronda ${ }^{50}$ (figura 13.4).

* Espacio de paso de tierra. Parte del camino de ronda del lado oriental de la fortaleza tardo-islámica.

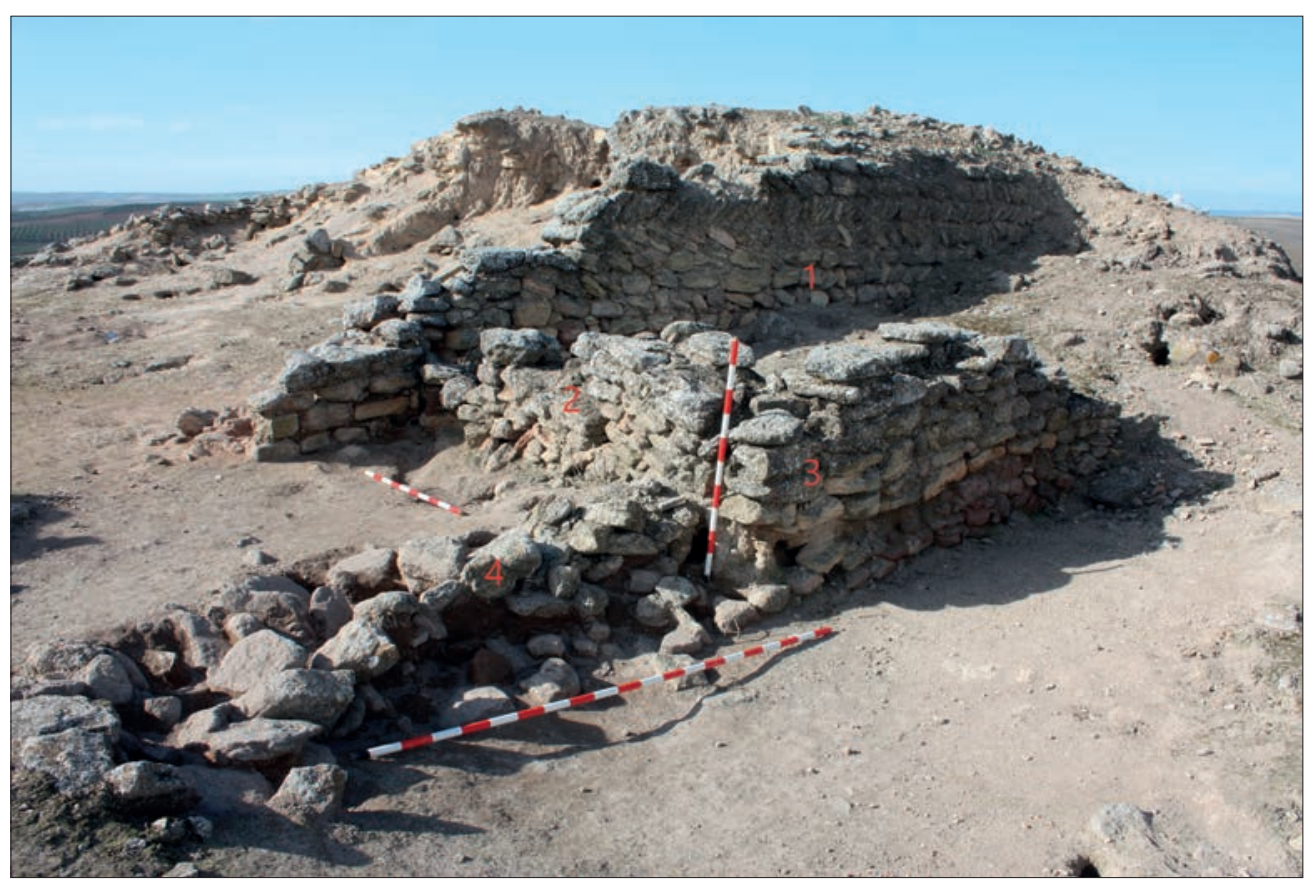

FIGURA 13. ESTRUCTURAS Y ESPACIO DE HABITACIÓN EN EL CAMINO DE RONDA DEL LADO ORIENTAL DE LA FORTALEZA TARDO-ISLÁMICA. (C) I. Carrasco

Estas estructuras pudieron formar parte de lo que debió ser el camino de ronda oriental de la muralla tardo-islámica, si bien algunas de ellas pudieron ser construidas durante los últimos momentos de ocupación histórica del yacimiento. El trazado de este camino de ronda, de 8,7 $\mathrm{m}$ de anchura máxima, es visible en toda la zona

48. UE 12 del Sector 1_2 según informe preliminar de esta intervención depositado en la Delegación Territorial de Cultura y Patrimonio Histórico firmado por la directora de la misma Dña. I. Carrasco (Vid. figura 11).

49. UE 13 del Sector 1_2 según informe preliminar de esta intervención depositado en la Delegación Territorial de Cultura y Patrimonio Histórico firmado por la directora de la misma Dña. I. Carrasco. (Vid. figura 11).

50. UE 14 y 15 del Sector 1_2 según informe preliminar de esta intervención depositado en la Delegación Territorial de Cultura y Patrimonio Histórico firmado por la directora de la misma Dña. I. Carrasco. (Vid. figura 11). 
afectada por las excavaciones antiguas ${ }^{51}$. Durante los años 80 se localizaron 47 metros de longitud de ese paso y con ello se observó que su trazado había afectado a una parte considerable del edificio protohistórico. Es previsible que rodee todo el perímetro amurallado oriental. La cota de uso de este adarve se situaba a 303,75 m.s.n.m, cota marcada por la zapata de cimentación de la muralla hacia el interior. Es un camino no exento de problemática a la hora de su interpretación pues su trazado afecta al núcleo del edificio de la acrópolis, está cubierto todavía por lo que creemos terreras contemporáneas, atravesado por estructuras de las que no sabemos ni funcionalidad ni cronología y del que desconocemos su comportamiento en el ángulo Noreste la fortaleza. Tendrán que ser futuras excavaciones las que completen su estudio y profundicen en su interpretación (Vid. figura 7).

\subsubsection{Lado Este}

* Son visibles 7,Io m de tramo de muralla, sobre la que se levanta, en la esquina norte, parte de lo que fue un cajón de tapial construido seguramente durante la remodelación de la fortaleza tardo-islámica, si bien es posible que este tramo pudiera haberse levantado o reparado en época bajomedieval. Al exterior lo que es visible son 16 hiladas de mampuesto de calcarenita del núcleo de la cerca -del que no podemos confirmar su fecha de construcción-. Su cara oriental está perdida. Hacia el interior son visibles seis hiladas de mampuesto (figura I4).

\subsubsection{Zona central}

* Relleno correspondiente al interior del edificio de la acrópolis formado de piedras y tierra de naturaleza arcillosa. Existe un hueco abierto por la entrada de agua y el arrastre del sedimento arcilloso. Derrumbes de estructuras arqueológicas (figuras IO y I2.I).

\subsubsection{Perfil sur. De oeste a este (figura I2.3)}

* Coronamiento de cajón 3.

* Relleno del interior de la acrópolis.

* Niveles sedimentarios.

* Estructura de dirección norte-sur. Seguramente se trate del núcleo de la acrópolis ${ }^{52}$.

* Rellenos sedimentarios.

* ¿Relleno interno de la acrópolis?

51. Camino No 68 de Ategua (Fuertes y Meyer 2019: 71, figuras 8 y 9) (Vid. figura 6).

52. UE 23 del Sector 1_2 según informe preliminar de esta intervención depositado en la Delegación Territorial de Cultura y Patrimonio Histórico firmado por la directora de la misma Dña. I. Carrasco (Vid.figura 11). 


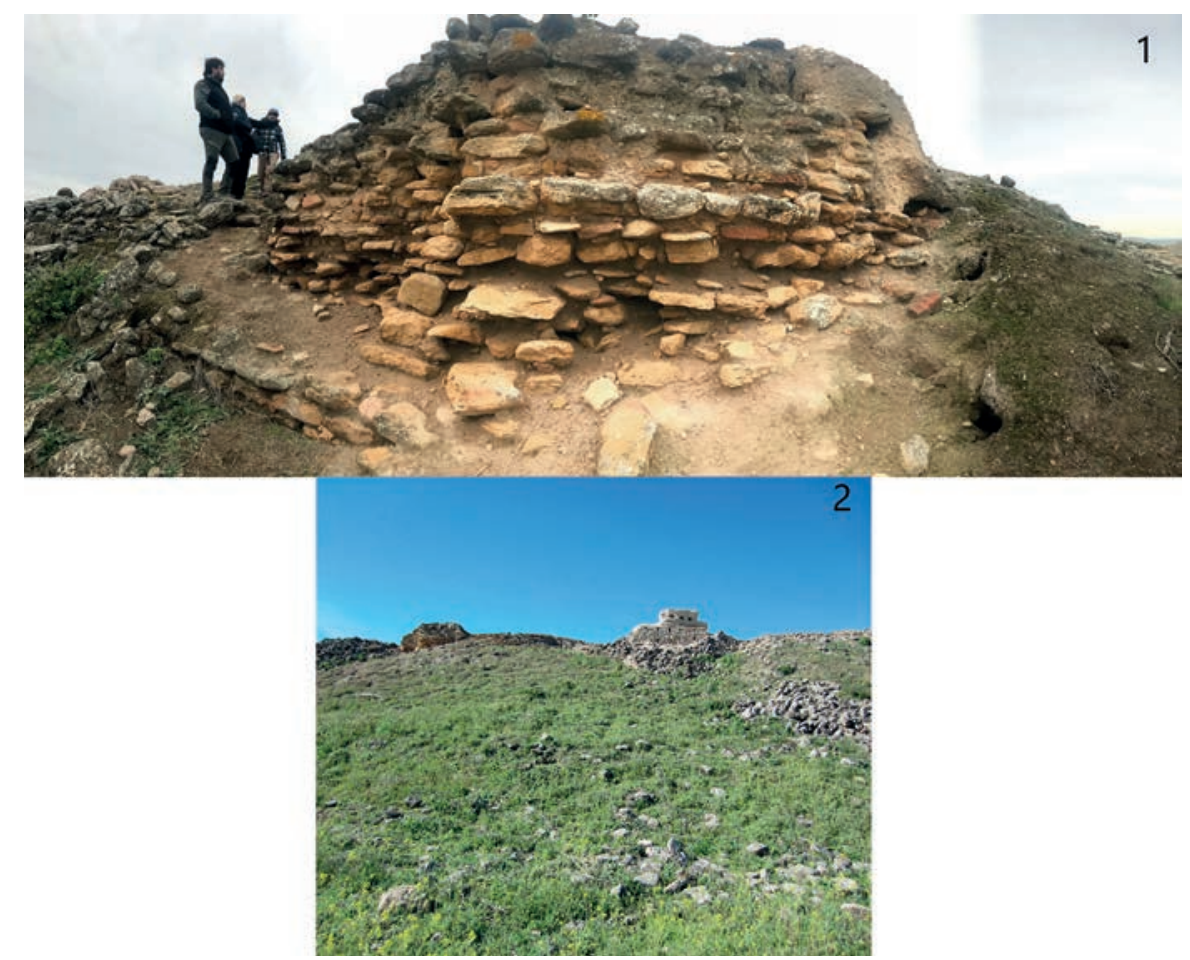

FIGURA 14. 1. TRAMO DE LA CERCA ORIENTAL DE LA FORTALEZA TARDO-ISLÁMICA ANTES DE LA CONSOLIDACIÓN. (C) I. Carrasco

2. DESDE EL SUELO DEL YACIMIENTO VISTA DE LOS DOS TRAMOS EN ALZADO DEL LADO ORIENTAL DE LA CERCA TARDO-ISLÁMICA. C M. ${ }^{a}$ C. Fuertes

\subsection{LA FORTALEZA TARDO-ISLÁMICA Y LA TORRE 8 (Figuras $\mathrm{I}, 3$ y 7$)^{53}$}

La construcción de la torre 8 de la fortaleza tardo-islámica, la identificada con la torre del homenaje de la misma, y el frente noreste de esa fortaleza en cuyo ángulo se construyó otra torre, la identificada con el número ıo, afectó de lleno a la acrópolis protohistórica cuyo material constructivo sirvió para realizar la obra más moderna. La torre 8 fue excavada en los años 8 o del pasado siglo y los materiales de su zanja de cimentación, de factura almohade, parece que dejan clara la cronología de su construcción en ese momento - finales del siglo XIl- principios del siglo XIII.

Es de planta rectangular de II x 7,20 m de lado ( 35 x 23 pies islámicos) y conserva una altura máxima de alzado, en su cara oeste, de I,9 $\mathrm{m}$. La fábrica es similar a la de la acrópolis, lógico por otra parte por cuanto la mayor parte del material fue reutilizado de aquella. Se construyó a base de mampuestos trabados con mortero pobre de cal, muy perdido, alineados en hiladas y calzados en algunas zonas con

53. Sobre la misma Fuertes 2017. Un primer acercamiento a la fortaleza tardo-islámica en Fuertes et al. $2011: 184$ y ss. Sobre las obras realizadas en 2019-2020 véase Carrasco et al. 2019. 
ripios para mantener la horizontalidad. Las esquinas están reforzadas con sillarejos de mayor tamaño.

Su construcción necesitó de la apertura de zanjas de cimentación sobre el terreno preexistente que, en la zona occidental, alcanzaron los io metros de profundidad. Su superficie de uso, hoy perdida, debió coincidir, más o menos, con la del camino de ronda. Desconocemos como se comportaba en alzado, ni si éste se construyó también con mampostería o con tapial -como el resto de las torres y de la cerca de esta fortaleza- o con una alternancia de ambos. Desconocemos la altura que tuvo si bien suponemos que como poco, alcanzó la más alta de Ategua, la de la cumbre de la acrópolis.

Son muy pocos los datos con los que contamos para entender cómo se articulaba el espacio interno de la fortaleza. Por los materiales cerámicos asociados a algunas de las estructuras que se localizan a día de hoy a pie de la acrópolis, podemos intuir que aquella contaba con una serie de espacios, posiblemente articulados a través de calles y espacios abiertos, que la organizaban. A día de hoy nos resulta imposible determinar si esas habitaciones estaban dedicadas a actividades relacionadas con el edificio o si uso era de carácter privado pero su existencia confirma la utilización de la acrópolis hasta el abandono de la ciudad de Ategua ${ }^{54}$.

\subsection{EL MORTERO DE CAL DE LA CUMBRE DE LA ACRÓPOLIS}

En varios puntos de la cumbre de la acrópolis, en los perfiles oriental y septentrional de la misma abiertos a causa de las obras de construcción de la fortaleza tardo-islámica y junto a su ángulo noreste, son apreciables restos informes, de gran tamaño en algunos casos, de un mortero de cal de apariencia muy similar al opus caementicium, pero de gran ductilidad, en el que son apreciables restos de mampuestos e incluso de cerámica formando parte del mismo.

En todos los casos, este mortero está afectado por las obras de la torre 8 y del camino de ronda, por lo que su presencia indica que su formación es anterior a esas dos actuaciones en concreto. Por el momento, no hemos llevado a cabo ningún

54. En la obra llevada a cabo en 2018-2019 fueron recalzadas con ladrillo y consolidadas con mortero tres estructuras adosada al cajón 13 de la acrópolis. Los tres paramentos parecen formar una planta en $U$-debida a su adosamiento a la pared ataluzada- que delimitarían tres espacios diferentes alienados de norte a sur y que durante su excavación estaban asociados a un derrumbe de tejas con presencia de materiales modernos y medievales. Otros dos muros probablemente medievales se localizaron en el conocido como corte CM G16. El paramento del perfil sur, de dirección sureste-noroeste, conservaba 4,1 m de longitud y gran parte de su alzado se había desplomado antes de comenzar las obras de consolidación, por lo que se consideró oportuno volver a levantarlo manteniendo su imagen antigua con el fin de garantizar la estabilidad del perfil sur del corte. Sabemos que se apoyaba en el cajón 8 de la cara oeste de la acrópolis y que, por lo tanto, se construyó después de esa pared. De similares características es el paramento que recorre el perfil norte del corte, con dirección, al igual que el anterior, sureste-noroeste y que tras su excavación quedó sostenido sobre un perfil de tierra. Se apoya directamente sobre el muro de talud de la fachada oeste de la Acrópolis y del mismo se conservan 2,66 m de longitud, con una anchura de $0,77 \mathrm{~m}$. y una altura de 1,67 m. Al carecer de un suelo asociado en la zona excavada, no podemos determinar su alzado, si bien éste podrá ser controlado cuando se intervenga arqueológicamente al norte del mismo. Los dos paramentos delimitaron espacios en sus lados norte y sur respectivamente $y$, tal vez, generaron un espacio intermedio entre ambos (Fuertes 2017: 29 y ss., figs. 15-18; Borrego 2019). 
trabajo en el ángulo noreste de la fortaleza tardo-islámica que nos haya permitido establecer alguna relación estratigráfica del mortero allí presente con el resto de estructuras y sedimentos.

La gran extensión del mismo, la ductilidad de la obra, el color blanco de su núcleo y los restos de piedra y de otros materiales inorgánicos como cerámica, nos permiten plantearnos que nos encontramos ante una gran calera, de la que no conocemos la superficie total que abarcaba y que, en principio, por lo que podemos observar, parece que en, línea recta, de norte a sur, ocupaba más de $30 \mathrm{~m}$ de longitud.

Su situación en la cumbre y la gran extensión que ocupa puede ser debida a que estuviera relacionada con la enorme obra que supuso la construcción de la fortaleza tardo-islámica, edificación que no solo ubicó una parte de la misma en el mismo sitio en el que se alzaba la acrópolis, sino que utilizó su material edilicio para la construcción de los cimientos y zócalos de la nueva edificación. La cal necesaria para fabricar el mortero de las juntas, para los enlucidos y para los cajones de tapial que se alzaban sobre los zócalos de la cerca, de los baluartes y de las torres defensivas, se pudo haber elaborado en esa ubicación. Para conseguirlo se debió utilizar todo el material constructivo sobrante tanto del edificio protohistórico como del resto de los edificios romanos. Sobre esta calera tendremos más información cuando se consigan retomar los trabajos arqueológicos.

\section{CONCLUSIONES (Figura I5)}

A pesar de que la intervención arqueológica llevada a cabo sobre la acrópolis ha sido de carácter menor y ha estado asociada a las necesidades derivadas de la obra de conservación del edificio, los resultados de la misma han permitido vislumbrar con mayor claridad su cronología y su evolución a lo largo de la historia.

La acrópolis se construye en el frente oriental de la ciudad de Ategua. Se trata de una colina artificial que se levanta al menos $9 \mathrm{~m}$ sobre la rasante del suelo de su construcción consiguiendo una cima desde la que se controla un territorio en más de $5 \mathrm{~km}$ a la redonda y desde la que se asegura el control visual, en tres cuartas partes de la circunferencia, de hasta I9 $\mathrm{km}^{55}$. Su función además de ver, fue la de ser vista. Desconocemos, por el momento, si sobre su cumbre se levantó algún edificio o hito que diera sentido religioso / político / mágico al edificio. La obra alcanzó en la antigüedad dimensiones mucho más amplias que las observadas hasta el momento y que ahora mismo no son perceptibles a simple vista.

El edificio pudo haber sido construido durante el Hierro I. Si bien son muy escasos los fragmentos cerámicos asociados a los niveles constructivos, todos ellos arrojan una cronología que oscila entre los siglos VIII-VII a.d.e. u VIII-VI a.d.e. La escasez de materiales diagnosticables recuperados nos hace ser prudentes a la hora de fechar su construcción, aunque la técnica edilicia del edificio y la cronología

55. Sobre la visibilidad del territorio que desde Ategua se controla, véase Fuertes et al. 2011: 153 y ss., fig. 12. 
de la cerámica le auguran un origen protohistórico, tal vez coincidente con el propuesto para la famosa estela de Ategua ${ }^{56}$.

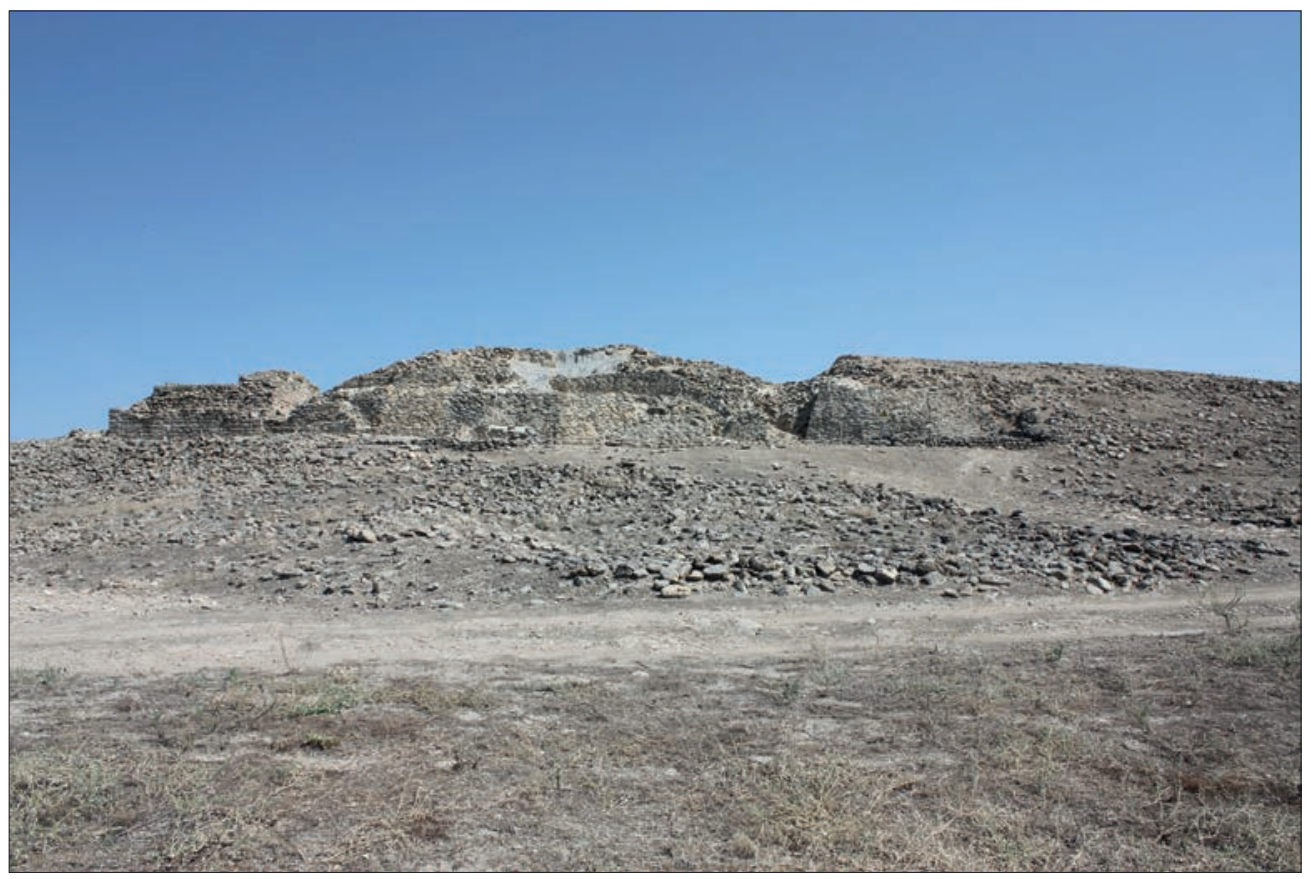

FIGURA 15. FRENTE OCCIDENTAL DE LA ACRÓPOLIS TRAS LAS OBRAS DE RESTAURACIÓN Y CONSOLIDACIÓN. (C) M. ${ }^{\mathrm{a}} \mathrm{C}$. Fuertes

Si se confirma esa cronología para el lado occidental del edificio, es más que probable que se pueda confirmar la misma para su lado oriental. En este lado la acrópolis funciona, además, como muralla y forma parte de la gran cerca indígenoromana que rodea a todo el cerro. De esta muralla sabemos su uso continuado durante las etapas históricas que preceden a su construcción hasta el abandono de la ciudad en el siglo XV.

La técnica edilicia utilizada para su construcción: mampuestos de mediano y pequeño tamaño trabados con arcillas margosas y su diseño arquitectónico -el del lado occidental, el único excavado hasta el momento-, a base de cajones de tres lados, casi siempre ataluzados, adyacentes unos con otros en diferentes planos arquitectónicos y de forma escalonada, nos recuerda al diseño constructivo de la Motilla de Azuer -2.200 ca.-I.500 ca. a.d.e-, a base de hiladas horizontales, de mampuestos trabados con las arcillas de la zona, que levantan paredes ataluzadas que se apoyan unas en otras para otorgarles mayor solidez (Nájera y Molina 2004: I83 y ss.; de Haro 20II). Somos plenamente conscientes de la distancia cronológica, cultural y geográfica que separa el edificio cordobés del manchego. Sin embargo, las similitudes edilicias son tan similares que no podemos dejar de hacer alusión

56. Propusimos por primera vez la posibilidad de que el edificio y la estela pudieran estar relacionados en una publicación divulgativa, impulsada por el Museo Arqueológico de Córdoba, durante la primera ola de la pandemia de COVID en 2020 (Fuertes 2020). 
a ellas a la espera de que nuevas intervenciones arqueológicas permitan ahondar más en el conocimiento del edificio cordobés.

Son muy escasos los datos sobre la manera en la que el edificio fue utilizado durante las etapas ibera y romana. De la primera etapa, tal y como hemos apuntado más arriba, parece que al menos uno de los tramos de la pared occidental formó parte de una vivienda o taller. De la siguiente etapa se han recuperado varias balas de catapulta romanas utilizadas para reparar tramos dañados de los cajones ataluzados, no obstante, por el momento, resulta imposible determinar la fecha concreta de esos arreglos al no estar vinculados con material diagnosticable. Es sugerente pensar en que los daños sobre este edificio y el resto de la ciudad, fueron efectuados por las máquinas de guerra cesarianas e, igualmente, en que para su reparación se utilizó el material de guerra en desuso.

La acrópolis vuelve a tener un gran momento de esplendor cuando se decide construir la fortaleza tardo-islámica y ésta apuesta para su construcción con utilizarla como lado oriental de la misma. En ese lado se alzan nuevos tramos de cerca sobre los más antiguos utilizando para ello la técnica del tapial. De los mismos son visibles, por el momento, dos de ellos. Su extremo sur será utilizado para construir la puerta sur de esa fortaleza, flanqueada por dos torres mientras que su lado más septentrional será desmontado para construir sobre él la torre del homenaje y el nuevo ángulo nororiental de la fortaleza tardo-islámica, reforzado por una torre -la io-.

En el interior de la fortaleza tardo-islámica se levantaron distintas dependencias de las cuales algunas se adosaron a los muros talud del frente occidental ${ }^{57}$.

Está claro que para abordar la complejidad arquitectónica, interpretativa, histórica y cronológica de la acrópolis es necesario el concurso de nuevas excavaciones que tendrán que ser las que diriman todos los detalles históricos de este magnífico y único edificio. Desde su construcción hasta el abandono final de la ciudad fue reparado y reaprovechado. Su función defensiva y como vigía aseguró su pervivencia.

57. Vid.nota 57 . 


\section{BIBLIOGRAFÍA}

Asensı, M. J. 2008: «Actividad Arqueológica preventiva tipo control de movimientos de tierras dentro del proyecto de consolidación del recinto amurallado de Ategua, Santa Cruz». Anuario Arqueológico de Andalucía 2008: II82-II98.

Blanco, A. I983: «Ategua». Noticiario Arqueológico Hispánico I3: 93-I35.

Borrego, J. D. 2018 (e.p): «Control arqueológico de movimientos de tierras, sobre obras de conservación y consolidación urgente en la cara oeste de la acrópolis del yacimiento arqueológico de Ategua, Córdoba».Anuario Arqueológico de Andalucía.

CARrasco, l. et al. 2019 (e.p.): «Actividad arqueológica preventiva en el Enclave Arqueológico de Ategua (Córdoba)». Anuario Arqueológico de Andalucía.

Córdoba, R, 2005: «El Hábitat de Teba (Santa Cruz, Córdoba) en época medieval., Arte, Arqueología e Historia I2: I02-IIO.

DE HARO, M. 20II: La puesta en valor de yacimientos arqueológicos de la prehistoria reciente en el sur de la península ibérica, Granada. Tesis doctoral: http://hdl.handle.net/I048I/20I98

Fuertes, C. 2014 (e.p.): «Control de movimientos de tierras de apoyo a la Obra Menor de conservación y consolidación ABl/305/2014. Enclave Arqueológico de Ategua, Córdoba». Anuario Arqueológico de Andalucía.

Fuertes, C. 20I5-20I6: «ATEGUA». Tríptico on-line: http://www.juntadeandalucia.es/cultura/ web/html/sites/consejeria/AAIICC/Galerias/Adjuntos/reca/folleto_ategua_web.pdf.

Fuertes, C. 20I7: «Ategua. Las grandes campañas de excavación de los años 80 en Ategua: la Acrópolis», Romula I6: 7-76.

Fuertes, C. 2020: «La estela de Ategua», Ciclo Mi pieza Favorita, Museo Arqueológico Provincial de Córdoba, 2020.

http://www.museosdeandalucia.es/web/museoarqueologicodecordoba/actualidad/-/asset_publisher/ ZVXoIwd7N39N/content/mi-pieza-favori-9?inheritRedirect=true

Fuertes, C. y Márquez, C. 2018 (e.p.): «Actividad Arqueológica en la modalidad de Documentación de Yacimientos Arqueológicos, para documentación planimétrica y ejecución de modelos 3D del Enclave Arqueológico de Ategua y para estudio geotécnico en la Parcela 8 del Polígono 49 del entorno BIC de la Zona Arqueológica de Ategua. Enclave Arqueológico de Ategua, Córdoba». Anuario Arqueológico de Andalucía.

Fuertes, C. y Meyer, C. 20i9: «La ciudad romana de Ategua. Análisis e interpretación de los resultados obtenidos por la prospección geofísica efectuada al interior de su recinto amurallado». Romula I8: I-4I.

Fuertes, C. et al. 20II: «Aproximación arqueológica al yacimiento de Ategua (Córdoba)». Romula I0: I35-198.

Gómez, L. 2011: «Las termas de Ategua (Santa Cruz, Córdoba)»». Romvla Io: 199-218.

López, L. A. 2008: Ategua (Córdoba): Protohistoria y romanización. Memoria de la actividad arqueológica puntual en el proyectado camino de acceso al Yacimiento. Campaña 2004. Sevilla.

Martín Bueno, M i983: «Primeros resultados en las excavaciones de Ategua (Córdoba)». En Homenaje a Martín Almagro Basch. Ministerio de Cultura. Madrid: 227-233.

Martín Bueno, M. y Cancela M. L. I983: «Apuntes al recinto medieval de Ategua». En XVI Congreso Nacional de Arqueología. Universidad de Zaragoza. Seminario de Arqueología. Zaragoza: 999-1009.

Martín de la Cruz, J. C. et al. 20 I7 (e.p.): «Memoria final del Proyecto de investigación y difusión de los bienes muebles procedentes de las excavaciones del despoblado de Ategua 
(Santa Cruz, Córdoba) conservados en el Museo Arqueológico de Córdoba (MACO)». Anuario Arqueológico de Andalucía.

Martínez R. 20I4: «La ocupación prehistórica». Torreparedones-Baena, Córdoba. Investigaciones Arqueológicas (2006-2012): 19-2I.

Martínez, R., Pérez G. y PeÑA-Chocarro, L. 20I4: «La campiña de Córdoba entre el IV y el I milenio ANE. Apuntes sobre la ocupación prehistórica del yacimiento de Torreparedones (Baena-Castro del Río, Córdoba). El sondeo 3, al norte del foro». Antiquitas 26: 135-I53.

NáJera, T. y Molına, F. 2004: «La motilla de Azuer. Un yacimiento de la Edad del Bronce en la Mancha». En R. García Huerta y F.J. Morales Hervás (coord.): La Península Ibérica en el II milenio a.C.: Poblados y Fortificaciones. Ediciones de la Universidad de Castilla-La Mancha. Cuenca: I73-2I4.

Penco, F., Valdivieso, A. y López, R. 2009 (e.p.): «Resultados de la Actividad Arqueológica Puntual correspondiente al Proyecto de consolidación del recinto amurallado de Ategua (Santa Cruz, Córdoba)». Anuario Arqueológico de Andalucía.

Rodero, S. 2007 (e.p): «Prevención y protección en el Yacimiento de Ategua: Actuación Arqueológica en la Parcela I, Polígono 49, Anuario Arqueológico de Andalucía III/ Actividades de Urgencia.

Ventura, Á. I994: «Ategua: ¿Municipio Flavio?». Anales de Arqueología Cordobesa 5: 305-3II. 
